Document downloaded from:

http://hdl.handle.net/10251/157576

This paper must be cited as:

Payri, R.; De La Morena, J.; Pagano, V.; Hussain, A.; Sammut, G.; Smith, L. (2019). Onedimensional modeling of the interaction between close-coupled injection events for a ballistic solenoid injector. International Journal of Engine Research. 20(4):452-469. https://doi.org/10.1177/1468087418760973

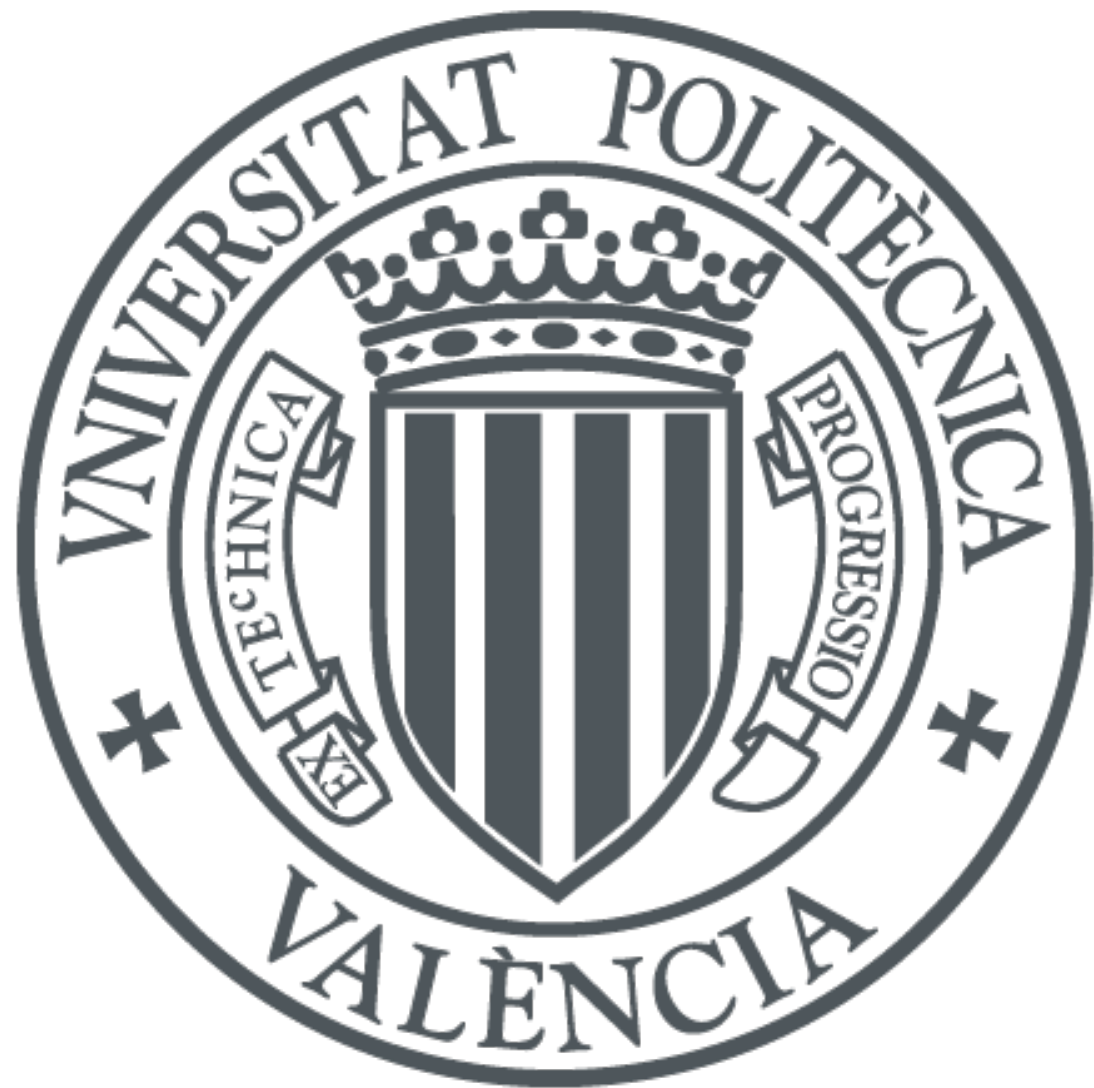

The final publication is available at

https://doi.org/10.1177/1468087418760973

Copyright SAGE Publications

Additional Information

This is the author s version of a work that was accepted for publication in International Journal of Engine Research. Changes resulting from the publishing process, such as peer review, editing, corrections, structural formatting, and other quality control mechanisms may not be reflected in this document. Changes may have been made to this work since it was submitted for publication. A definitive version was subsequently published as https://doi.org/10.1177/1468087418760973 


\section{D-modeling of the interaction between close-coupled injection events for a ballistic solenoid injector}

R. Payri ${ }^{1}$, J. De la Morena ${ }^{1}\left({ }^{*}\right)$, V. Pagano ${ }^{1}$, Ali Hussain ${ }^{2}$, Gilbert Sammut ${ }^{2}$,Les Smith ${ }^{2}$

${ }^{1}$ CMT-Motores Térmicos, Universitat Politècnica de València

Camino de Vera s/n, E-46022, Spain.

2 Jaguar Land Rover Limited

Abbey Road, Whitley, Coventry, CV3 4LF, UK.

(*) Corresponding author:

Dr. Joaquin De la Morena, joadela@mot.upv.es

CMT-Motores Térmicos, Universitat Politècnica de València

Camino de Vera s/n, E-46022, Spain.

Telephone: $+34-963877650$

FAX: +34-963877659 


\section{Abstract}

In the current paper, an investigation of a solenoid common-rail injector has been carried out to understand the hydraulic interactions between close-coupled injections events. For this purpose, a one-dimensional model of the injector was developed on GT-Suite software. The geometrical and hydraulic characteristics of the internal elements of the injector, needed to construct the model, were obtained by means of different custom-made experimental tools. The dynamic behavior of the injector was characterized using an EVI Rate of Injection meter. The hydraulic results from the model show a good alignment with the experiments for single injections, and a varied degree of success for multiple injections.

Once the model was validated, it has been used to understand the injector performance under multiple injection strategies. The mass of a second injection has shown to highly depend on the electrical dwell time, especially at low values, mostly due to the dynamic pressure behavior in the needle seat. The critical dwell time, defined as the minimum electrical dwell time needed to obtain two independent injection events, has been numerically obtained on a wide range of operating conditions and correlated to injection pressure and energizing time of the first injection. Finally, the increase in the needle opening velocity of the second injection compared to the single-injection case has been analyzed for close-coupled injection events. 


\section{Introduction}

Main challenge for Diesel engine design is to achieve a combined reduction of fuel consumption and exhaust emissions [1], [2]. For this purpose, the performance of the fuel injection system has shown to be critical [3]-[5]. Several authors have shown how the nozzle geometry has a significant effect on atomization and spray formation processes [6]-[8]. Some of these aspects are linked to the appearance of cavitation inside the nozzle [9]-[11]. Additionally, the design of the electrovalve and the internal elements of the injector influence its dynamic behavior [12]-[14].

Fuel injection system suppliers have followed two main development paths in the recent years. On the one hand, fuel injection pressure capability has increased over the last years [15]. New systems able to reach up to $300 \mathrm{MPa}$ show the potential for improved atomization and fuel-air mixing efficiency [16]-[18], which helps to reduce soot emissions [19], [20], and shorter combustion duration at high loads [8], which increases engine thermal efficiency and power density [21]. On the other hand, new injector technologies capable of developing complex multiple injection strategies have been developed. In this sense, the decomposition of the injection into multiple closed-coupled events allows a better control of the heat release shape, especially in the premixed phase, reducing combustion noise and NOx emissions [22]-[25]. Additionally, post and after injections are typically added to improve soot oxidation [26], [27] and/or to accelerate the warm-up of the exhaust aftertreatment or to trigger Diesel Particulate Filter (DPF) regeneration [28]. 
One of the aspects limiting the usage of close-coupled injection strategies is the hydraulic interaction between the injection events [29], [30]. Indeed, if an injection event is located very close to a previous one, the pressure equilibrium and initial deformations inside the injector are not recovered, modifying the boundary conditions for this second injection. For solenoid injectors, this is typically translated in a change in the opening ramp and the total hydraulic duration of the second event, resulting in a different injected mass than expected from a comparable single-injection test [30]. Unfortunately, the extent of these changes is sensitive to the specific injection train and boundary conditions used. For this reason, a comprehensive experimental campaign aimed at characterizing the interactions between close-coupled injection events is necessary, increasing engine development and calibration timings.

In the current paper, a methodology based on a one-dimensional fuel injector model [31] will be used to better understand the hydraulic interactions between the injections. For this purpose, the injection model will be first developed in the GT-Suite platform [32]. The dimensions of the internal elements of the injector will be measured by a combination of regular measuring devices, an optical microscope and a Scanning Electron Microscope, depending on the characteristic dimensions of each component and the level of accuracy required. The hydraulic performance of the key internal passages (mostly the control volume and nozzle orifices) are assessed on a wide range of operating conditions on a dedicated test rig. The rest of the injector model parameters will be calibrated to reproduce the transient injection rate profiles, measured through an EVI Rate of Injection meter. The transient effects, mainly caused by the eddy-current, cannot be neglected especially during switching on and off the supply current. A 
worthy approach is reported in the literature for modeling the solenoid injector, especially for the magnetic submodel, based on experimentally gained static magnetic force data. [40]. Once the model is finalized, an analysis of the interaction of close-coupled injection events will be performed, looking at the critical dwell time (defined as the minimum electrical separation needed to achieve two independent injection events), and the differences in the opening ramp and total injected mass at different sets of boundary conditions.

The paper is divided in 8 sections. Section 2 describes the different experimental techniques used to characterize the different elements of the injector. The 1D injector model layout is described in Section 3. Section 4 summarizes the hydraulic characterization of the main orifices (control volume and nozzle) together with the corresponding discharge coefficient correlations introduced in the injector model. Section 5 shows the model validation, including both single and multiple injection strategies. The hydraulic interaction between close-coupled injection events is analyzed in Section 6. The main conclusions of the study are drawn in Section 7. Finally, Section 8 shows some suggestions for further improvements. 


\section{Experimental methodologies}

In order to create the 1D fuel injector model, several experimental tests aimed at characterizing the different elements of the injector are needed. The most important techniques used for this purpose are summarized in this section.

\subsection{Internal geometry determination}

The first step needed to build a $1 D$ injector model is to perform complete geometric characterization of its internal elements. Most of the main internal dimensions of the injector are measured with the use of an optical microscope, adjusting the image resolution depending on the size of the element under examination. Additionally, a high-precision balance is used to obtain the masses of all the moving parts, and more particularly of the electrovalve armature and the piston and needle elements.

Nevertheless, a few of the internal flow passages are not directly visible after the complete dismantling of the injector, or are too small to be properly measured using standard metrology tools. Hence, a silicone molding technique previously developed and validated is used to characterize them [33]. The methodology consists of filling the corresponding orifices with a special silicone, allowing it to penetrate all along the cavity. Once the silicone dries out, the molds can be

extracted and analyzed using a Scanning Electron Microscope (SEM). Figure 1 shows an example of the application of this technique: from the control volume analysis, the inlet and the outlet diameters result equals to $0.187 \mathrm{~mm}$ and 0.227 $\mathrm{mm}$. The same process is performed with other injector internal elements, such as the nozzle orifices, the fuel feed duct or fuel return duct. 


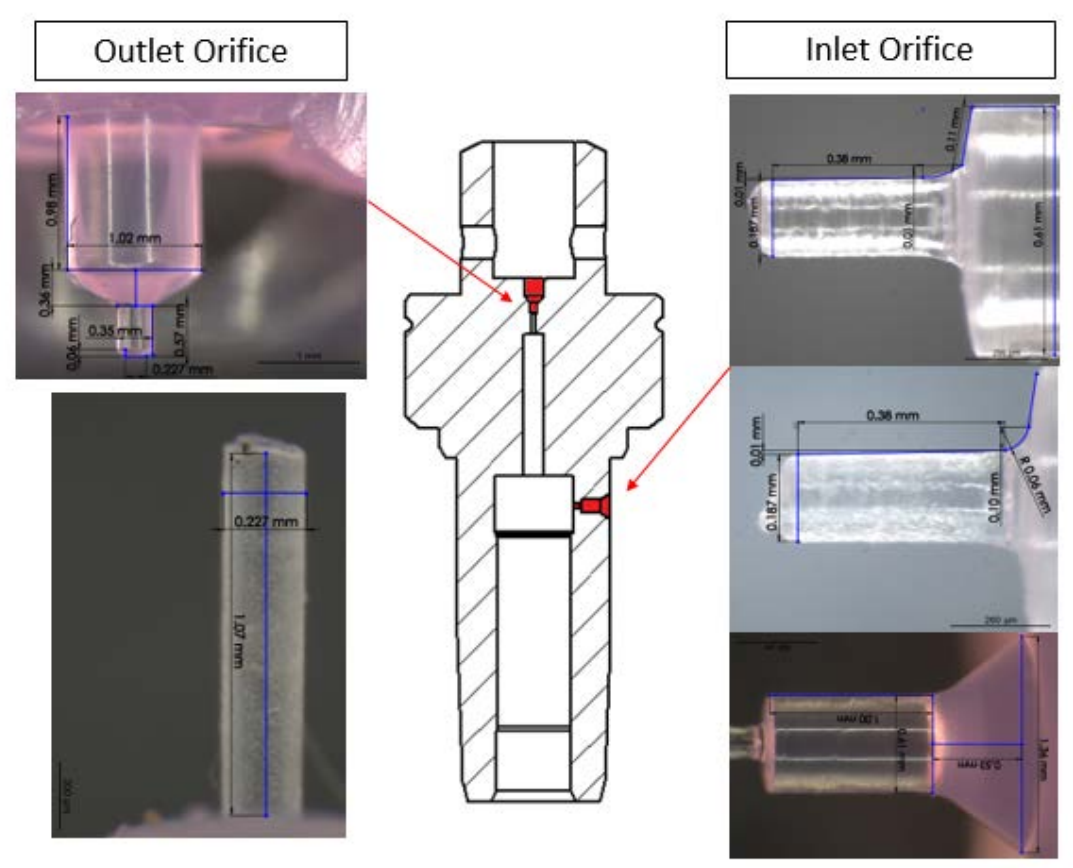

Figure 1. Silicone molds technique for control volume geometry determination

\subsection{Hydraulic characterization test rig}

Together with the fuel injector elements dimensions, it is also important to properly characterize the hydraulic behavior of the most important fuel passages inside the injector. This is particularly important for the control volume inlet (OZ) and outlet $(\mathrm{OA})$ orifices, since they affect the transient behavior of the pressure in the upper part of the piston rod and needle assembly. Additionally, the hydraulic characteristics of the nozzle orifices have a direct impact on the injection rate for a given set of boundary conditions. Note that these measurements contribute to the steady state nature of the injector with a lesser extent on the transient behavior of the injector/model. 


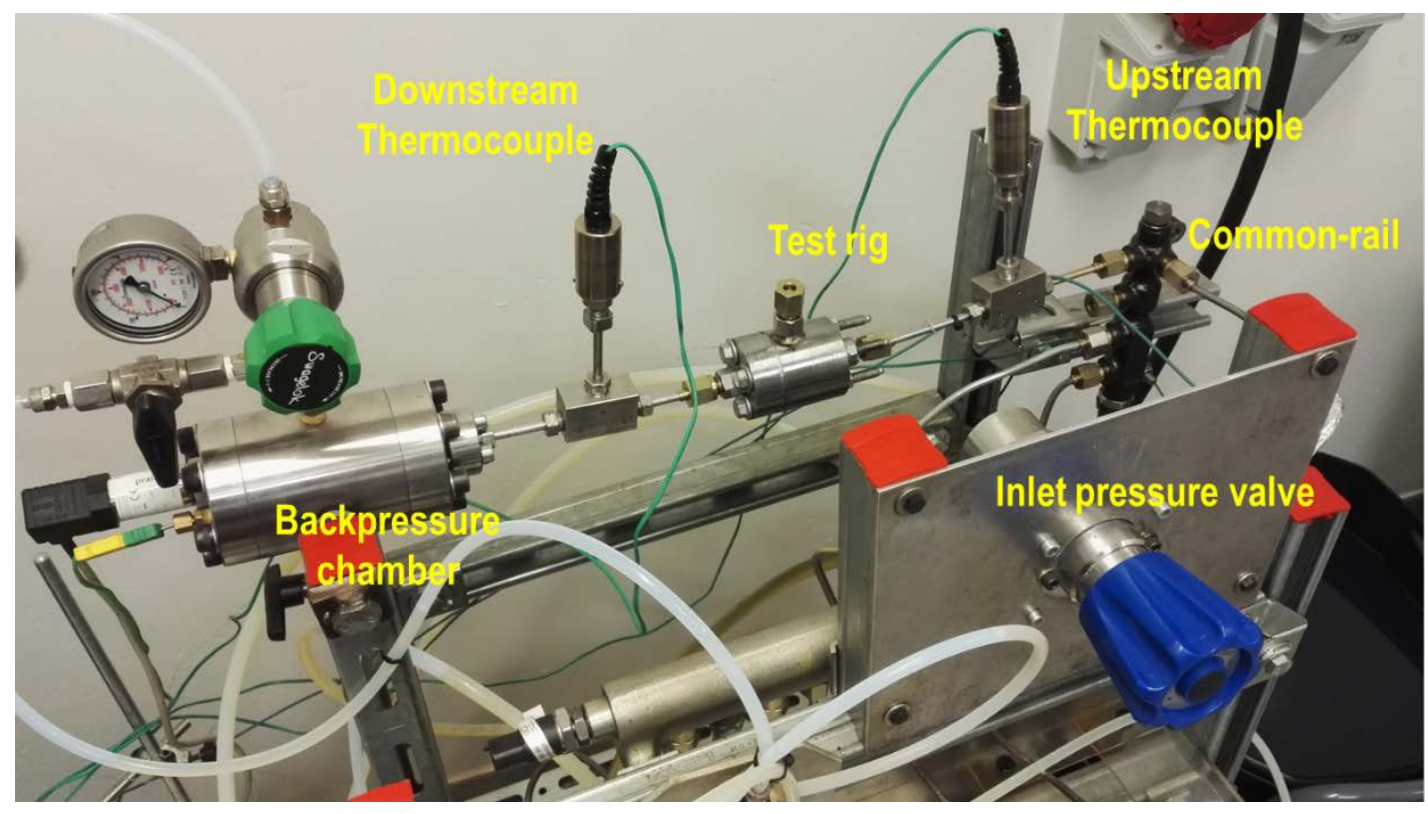

Figure 2. Hydraulic characterization test layout

Figure 2 shows the test bench used for this work. Two rotary pumps continuously supply the fuel to a common-rail, allowing a maximum operating pressure of approximately $80 \mathrm{MPa}$ in continuous flow conditions. A manual fine-pass valve allows to control the amount of flow arriving to the rail, and consequently the inlet pressure level. The common-rail outlet is connected to a custom-made test rig, which holds the internal element to be characterized (in the case of the current study, either the control volume or the nozzle). The outlet of the test rig is connected to a chamber, where another valve coupled with a pressure sensor allows to set the backpressure value for the experiment. Additionally, two thermocouples are available in the test rig inlet and outlet pipes. More details of this methodology can be found in [14]. 

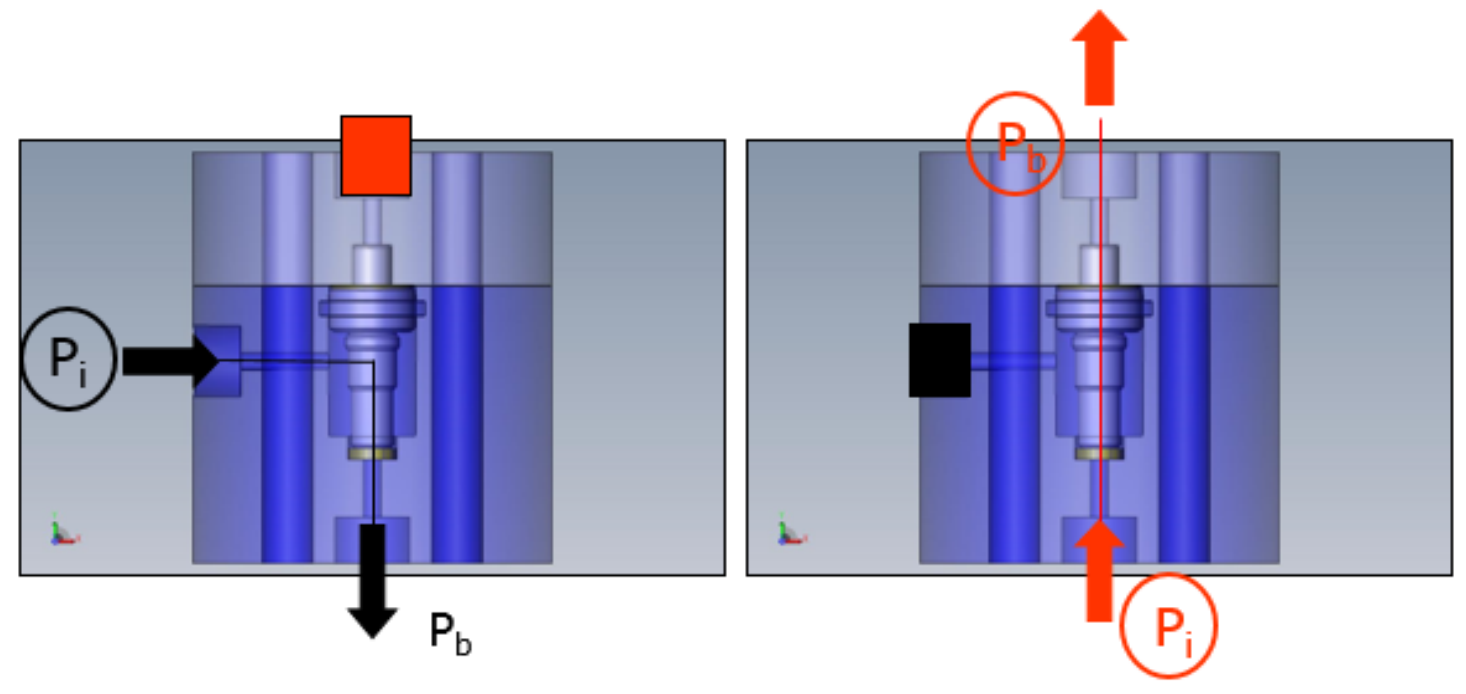

Figure 3. Schematic of control volume hydraulic test rig. Left: Inlet orifice (OZ) configuration.

Right: Outlet orifice (OA) configuration

Figure 3 shows the specific design of the test rig for the control volume hydraulic characterization. The control volume is mounted within a steel cylinder and the flow is forced to pass through it, following the same flow path as it would have during the real injector operation. For the inlet orifice (OZ) characterization, the flow enters through the inlet orifice, which is connected to the common-rail (at injection pressure or $P_{i n j}$ condition), and exits through the bottom, connected to the backpressure chamber (at backpressure or $P_{b}$ ). For this purpose, the outlet orifice (OA) is blocked with a tap. Contrarily, for the outlet orifice (OA) setup, the fluid enters from the bottom orifice and exits through the OA orifice. In the case of the nozzle orifices, the test rig is constructed so that the flow enters from the feeding orifice of the nozzle and exits simultaneously through all the discharge orifices.

In order to evaluate the orifices behavior, tests were performed with different values of injection pressure (ranging from 10 to $50 \mathrm{MPa}$ ). For each injection pressure value, the backpressure was varied from 0.1 to $9 \mathrm{MPa}$. This way, a very 
detailed characterization of all the orifices, including the eventual appearance of cavitation, has been performed.

\subsection{Rate Of Injection (ROI) meter}

Injection rate measurements at different conditions are needed to calibrate the dynamic behavior of the injector. In this measurement, a composite of different phenomena is investigated; these phenomena being classified into four subgroups: mechanical, hydraulic, magnetic and electric. The model has to reproduce these injection rate measurements to help distinguish between these different phenomena. For this purpose, a EVI Rate of Injection (ROI) meter based on Bosch long-tube methodology [34] is used. The injection event takes place inside a pressurized chamber with liquid fuel environment. A dynamic piezoresistive transducer captures the instantaneous pressure increase due to the injection event, which is proportional to the mass flow delivered by the injector. The chamber is connected to a long tube in order to avoid any interaction with the reflected pressure waves. The fuel exiting the ROI meter is directed to a highprecision balance, allowing to check the total mass delivered by the injector. During the current measurements, a total of 50 consecutive cycles were registered for statistical analysis. More details of the methodology can be found in [35].

The injection rate was evaluated in different conditions of injection pressure (30, 50, 100 and $180 \mathrm{MPa})$, backpressure (2.5, 5 and $8 \mathrm{MPa})$ and energizing time $(0.2,0.3,0.5$ and $1 \mathrm{~ms})$ for the single injection characterization. Additionally, several multiple injection strategies characterized by different dwell time values (0.15 ms< DT $<2 \mathrm{~ms}$ ) have been measured. 


\section{Model layout}

As mentioned earlier the ROI measurement was the result of a multitude of phenomena happening inside the injector, phenomena which are hard to distinguish from each other. The significance of the modelling effort is to link the steady state measurement (2.2) and other component characteristics to reproduce the transient behavior observed in the ROI measurements.

The one-dimensional model of the injector has been constructed based on the previous information in the literature [42] using the commercial software GT-Suite [32]. The model is composed of three main parts: the electromagnetic valve, the injector holder (which includes the fuel inlet lines, the control volume, the piston rod) the needle and the nozzle. The model layout for each of these elements is described in detail below. It is important to remember that not all the model coefficients are easy to calculate. Some examples may be the damping coefficients, electric resistance, magnetic reluctance or gap between assembled parts. Even some geometrical values may have some uncertainties linked to the dismantling process (as for example the springs preloads). All these coefficients can affect the transient behavior of the injector, so they were estimated by means of a wide range optimization study (starting from a theoretical analysis and previous model values). Appendix A summarizes some of the most important dimensions and parameters inside the model. 


\subsection{Electromagnetic valve}
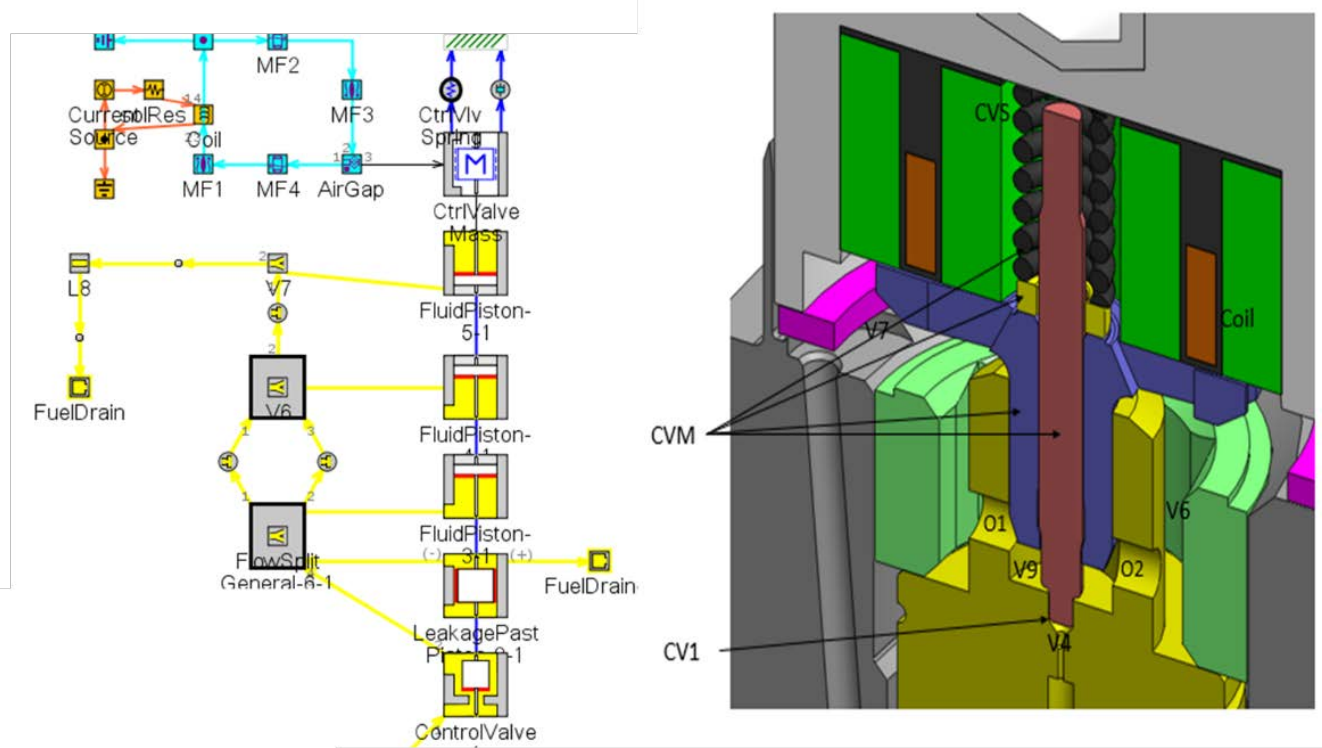

Figure 4. Electrovalve model layout

Figure 4 shows the model layout of the electrovalve. In the upper left part of the schematic, orange elements represent the electrical circuit, simplified by a current source, a resistance and a coil. The magnetic path from the coil to the armature is represented by MF1-MF4 magnetic objects. The AirGap object transmits the electromagnetic force to a single mass representing all the moving elements in the control valve (CtrlValveMass). FluidPiston objects are used to simulate the fluid-dynamic forces acting on the armature surfaces, and finally a flapper-valve template allows to model the interaction between the armature and the control volume outlet orifice $(\mathrm{OA})$. Some objects within the electrovalve model were based on actual measurement (such as coil resistance) while some others were purely geometrical (number of coils, coil wire diameter from slicing a solenoid etc.). It is important to point out that not all the electromagnetic submodel 
coefficients are easy to measure. Without specific instruments that would allow transient measurements (such as x-ray technology, Doppler vibrometer laser, accessible solenoid control valve), a sensitivity study was carried out to evaluate the most important parameters. First of all, the stator and armature internal geometry has been measured by cutting the electromagnetic element. Then an optimization study, starting from previous injectors models values, has been performed for a wide range of conditions. Last, in order to take into account the eddy currents generated due to the switch on and off of the supply current, a correlation for the internal resistance depending on the energizing time of the control valve has been implemented.

In the upper part of the armature, a spring is present to allow the control valve to close once the solenoid stops being energized. The stiffness of this spring is calculated based on its geometry, using the following formula:

$$
K_{\text {spring }}=\frac{G \cdot D_{A}^{4}}{8 \cdot N_{\text {turns }} \cdot D_{B}^{3}}
$$

Where $K_{\text {spring }}$ is the spring stiffness, $G$ is the Young modulus of the spring material, $D_{A}$ is the difference between the internal and external spring diameters divided by two, $N_{\text {turns }}$ is the number of coils and $D_{B}$ is the sum between the internal and external spring diameters divided by two. While this is one method to obtain the stiffness of the spring, a more direct method would have been to measure it on a force-displacement meter. This is discussed again in the section 8 of this document. 


\subsection{Injector body}
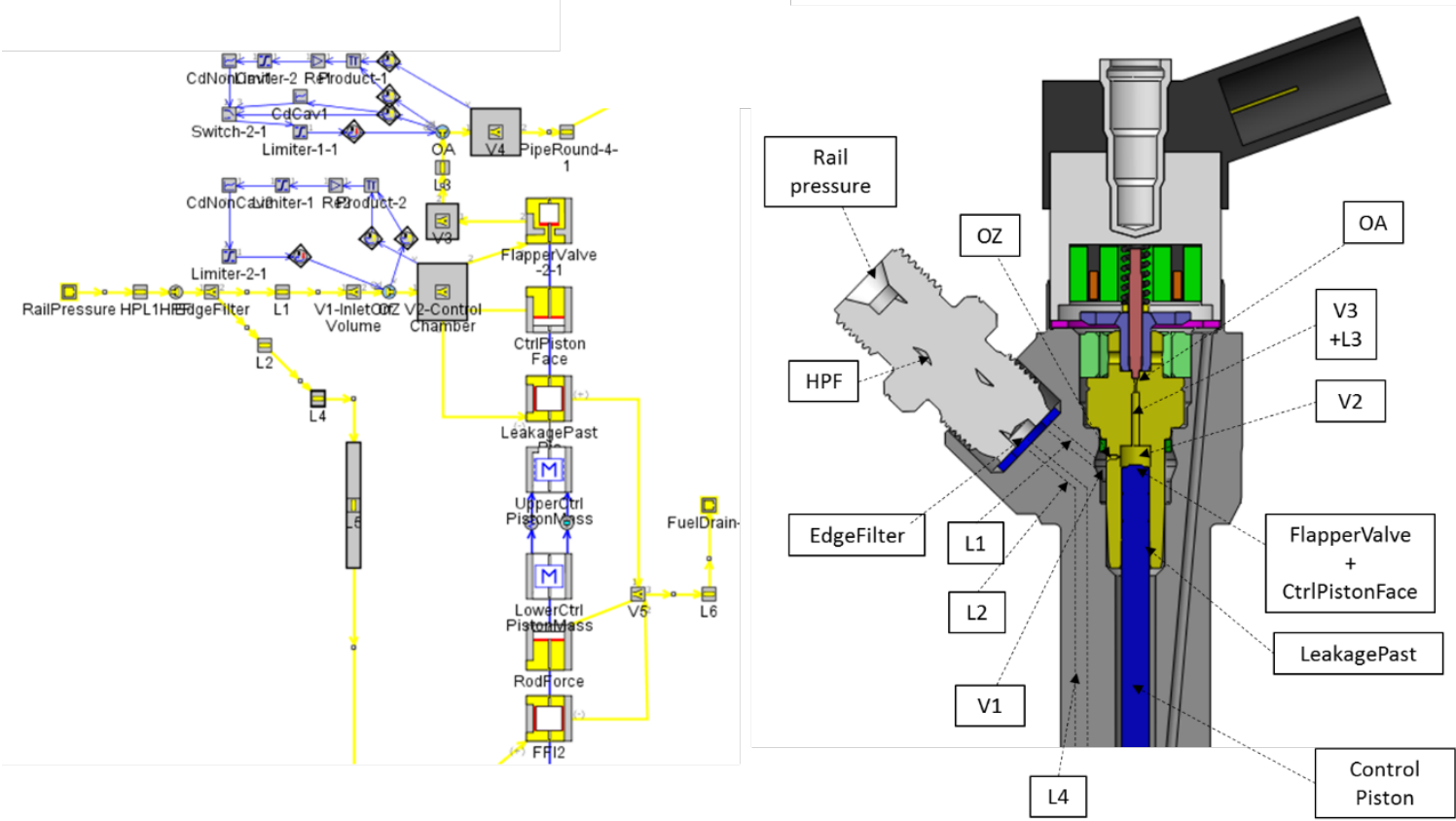

Figure 5. Injector holder model layout

Figure 5 details the model layout for the injector holder, which includes the fuel inlet line, the control volume and the piston rod mass. The RailPressure boundary condition includes the fuel temperature and pressure in the high-pressure line connecting the rail and the injector in the injection rate experimental setup. For simplicity, a constant pressure level has been included in the model, even though in reality some dynamic behavior of the pressure would exist.

For the OZ and OA orifices, a dedicated control logic is used to impose the discharge coefficient as a function of the Reynolds number or the cavitation number, depending on the particular operating conditions of the orifice. The aforesaid control logic has been implemented in order to obtain a better 
calculation of the discharge coefficient, as compared with GT-Suite internal logic (template "OrificeCavitatConn").

The specific equations used for this purpose will be introduced in Section 4.1. The piston is modeled using two independent masses, each one having $50 \%$ of the total mass of the element. A spring + dampener compound is used to take into account the mechanical deformation of the piston rod due to the different pressure forces acting on it. The spring element also take into account the piston rod stiffness, evaluated with the following formula:

$$
K_{\text {equiv,spring }}=\frac{1}{\frac{1}{E_{\text {steel }}} \cdot \sum_{i=1}^{N} \frac{L_{i}}{A_{i}}}
$$

Where Kequiv,spring is the spring equivalent stiffness, $E_{\text {steel }}$ is the Young Module of the steel, Ai and Li are respectively the section changes and their length along the injector body.

The upper section of the rod and its eventual interaction with the control volume V2 is modeled by the use of a flapper valve. Nevertheless, it has to be noted that the initial distance between the upper section of the rod and the lower part of the control volume is significantly large (around $2.5 \mathrm{~mm}$ ), so it is unlikely that the piston rod would reach the control volume surface in realistic injection conditions. Two FluidPiston objects are used to calculate the pressure forces associated with the different changes of diameter along the rod length. 


\subsection{Needle and nozzle}

The last portion of the model is the one corresponding to the needle and nozzle elements (Figure 6). In the upper part, a spring is present to ensure a correct needle closing once the injector stops being energized. Two mass objects are used to replicate the needle, with an intermediate spring and dampener to account for the needle initial deformation due to the initial pressure forces, as seen for the piston rod mass. The flow passages from the nozzle inlet to the sac volume are represented by objects NL1, NV1 and NL2.
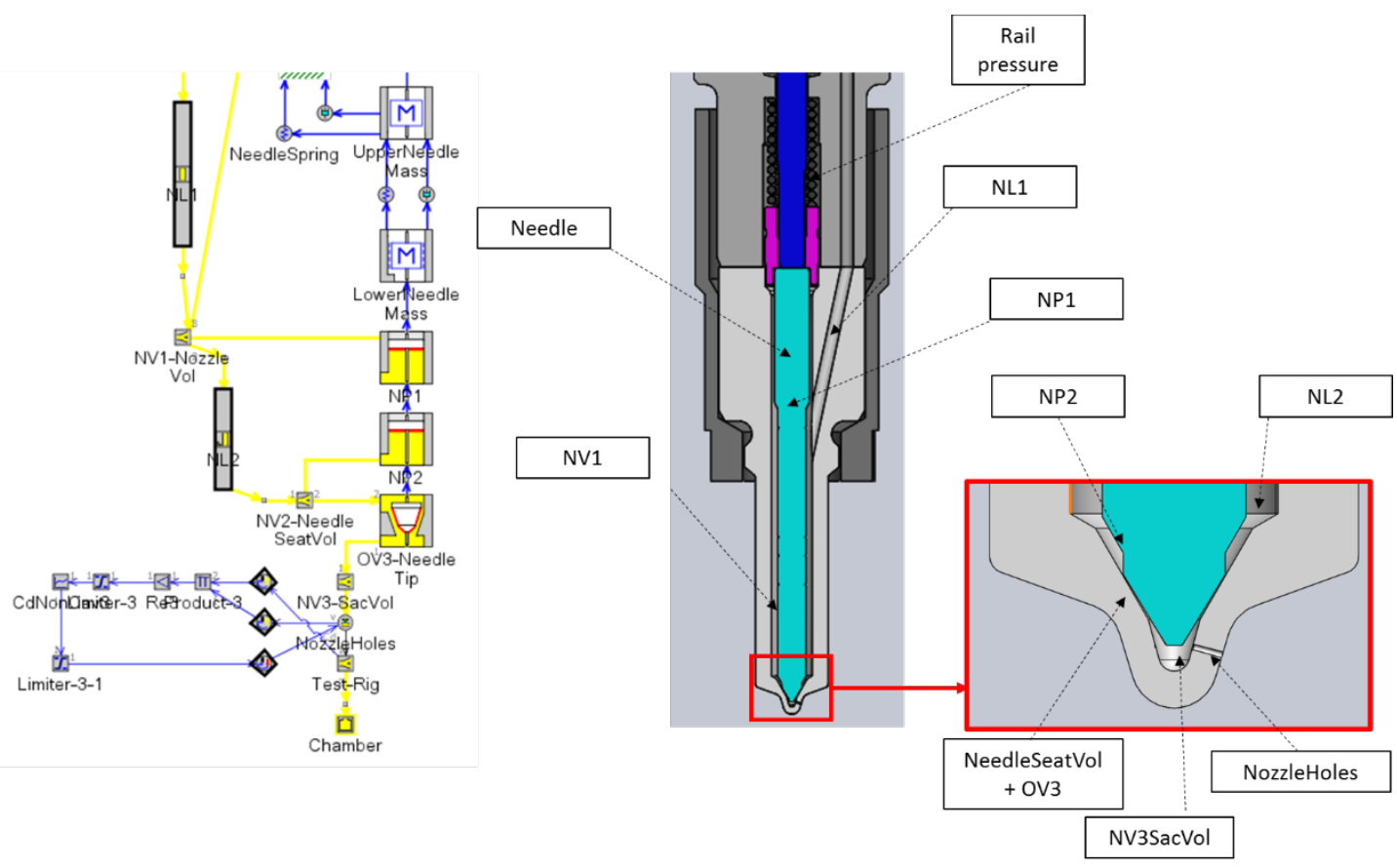

Figure 6. Needle and nozzle model layout

In the bottom part of the figure, the interaction between the needle, the sac and the nozzle orifices is detailed. The ConicalPoppetConSeat template is used to take into account the pressure losses along the seat section depending on the computed needle lift. NozzleHoles object calculates the flow through all the 
nozzle orifices (eight for the current hardware), with a discharge coefficient calculated depending on the Reynolds and Cavitation Number according to the experimental correlations found on the permeability tests (see section 4.1). Before setting the discharge boundary condition (Chamber), an object replicating the section of the Rate of Injection meter up to the pressure transducer is used.

\section{Hydraulic characterization results}

The main results obtained during the experimental characterization of the main injector orifices are summarized below. As mentioned earlier these measurements are steady state measurements (ie. having no description of transient behaviour).

\subsection{Control volume Inlet and Outlet orifices}

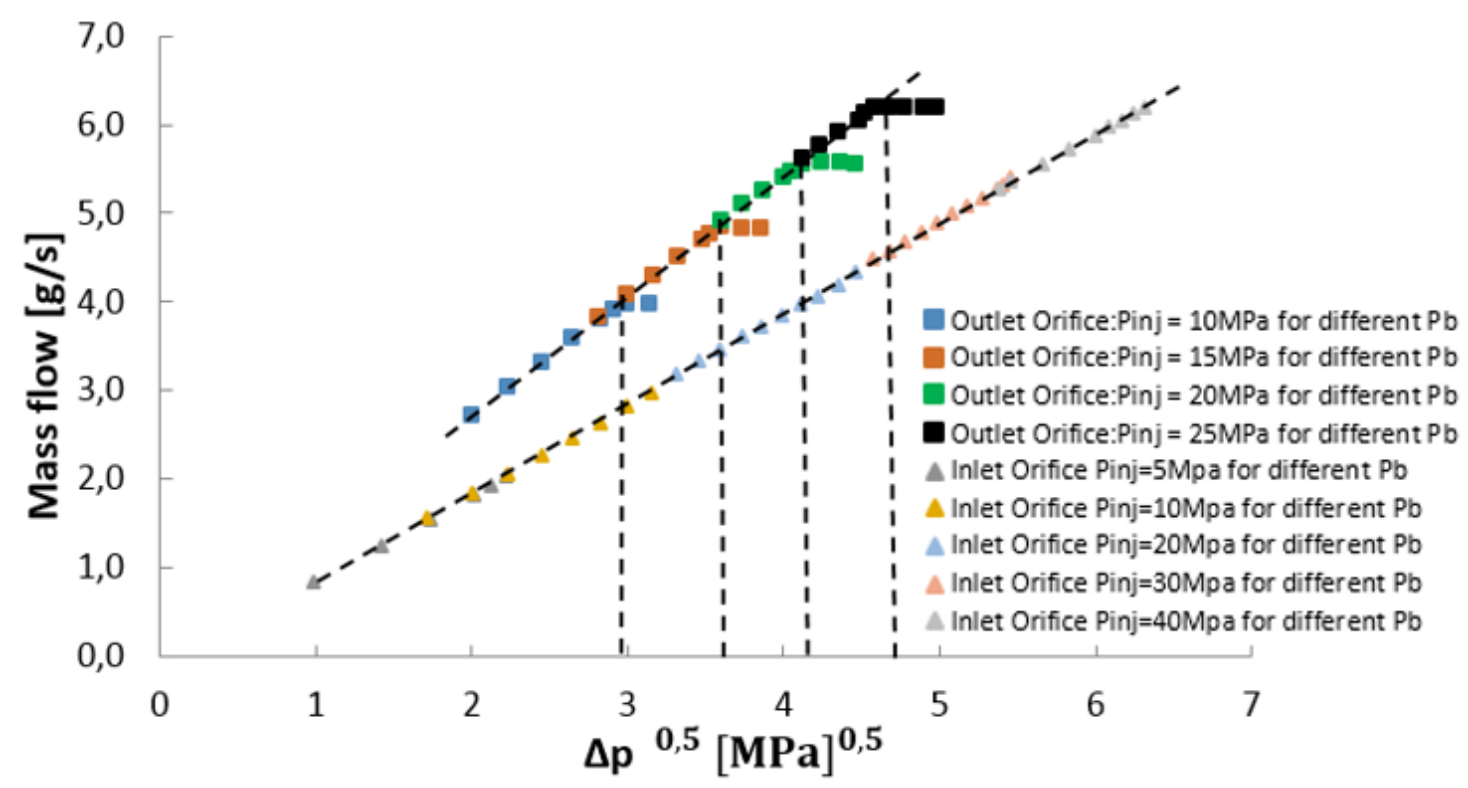

Figure 7. Steady-state mass flow for control volume orifices 
Figure 7 illustrates the results obtained from the hydraulic experimental campaign on the control volume orifices in terms of mass flow rate (through the orifice) vs. the square root of the pressure drop. The dependence is clearly linear for both orifices under no cavitation regime. The inlet orifice (OZ) avoids the appearance of the cavitation phenomenon thanks to its conical shape. In the case of the outlet orifice(OA), some mass flow choking induced by cavitation can be observed for all the injection pressure levels tested.

Once the mass flow has been calculated, the discharge coefficient can be obtained from the following expression:

$$
\dot{m}_{f}=C_{d} \cdot A_{0} \cdot \rho_{f} \cdot u_{B}
$$

Where $\dot{m}_{f}$ is the mass flow measured from the experiments, $A_{o}$ is the geometrical outlet section of the corresponding orifice, $\rho_{f}$ is the fuel density and $u_{B}$ is the theoretical velocity of the flow calculated from Bernoulli's equation:

$$
u_{B}=\sqrt{\frac{2 \cdot\left(P_{i n j}-P_{b}\right)}{\rho_{f}}}
$$

Thus, the discharge coefficient is calculated as:

$$
C_{d}=\frac{\dot{m}_{f}}{A_{0} \cdot \sqrt{2 \cdot \rho_{f} \cdot\left(P_{\text {inj }}-P_{b}\right)}}
$$

According to the literature [36], [37], the discharge coefficient of an orifice under non-cavitating conditions can be calculated as an asymptotic function of the Reynolds number as follows: 


$$
C_{d}=C_{d, \max }-\frac{A}{\sqrt{R e}}
$$

Where $C_{d, \max }$ and $A$ depend on the orifice geometry. The specific values obtained for the $\mathrm{OZ}$ and OA orifices, together with the R-squared value for the correlation, are summarized in Table 1. In the case of the Reynolds dependence for the OA orifice, the influence was found to be very small since the data was already in the asymptotic region for all the conditions tested, thanks to its higher diameter (and, consequently, higher Reynolds number).

Table 1. Correlation parameters for the discharge coefficient in non-cavitating conditions

\begin{tabular}{|c|c|c|c|}
\hline Orifice & $\boldsymbol{C}_{\boldsymbol{d}, \max }$ & $\boldsymbol{A}$ & $\mathbf{R}^{\mathbf{2}}$ [\%] \\
\hline OZ (inlet) & 0.953 & 10.07 & 97.3 \\
\hline OA (outlet) & 0.817 & $4 \mathrm{e}-3$ & 90.2 \\
\hline
\end{tabular}

When cavitation appears, the discharge coefficient loses its dependence with the Reynolds number due to the mass flow collapse phenomena [37], [38]. Under these conditions, it has been seen that the discharge coefficient can be calculated as:

$$
C_{d}=C_{c} \sqrt{K}=C_{c} \sqrt{\frac{p_{i n j}-p_{v}}{p_{i n j}-p_{b}}}
$$

Where $K$ is the cavitation number, $p_{v}$ is the vapor saturation pressure of the fuel and $C_{c}$ is the contraction coefficient, which again depends on the orifice geometry. The value of the contraction coefficient found for the OA orifice is 0.756, and the R-squared for the experimental correlation found based on equation (7) is $98.08 \%$. Finally, a critical cavitation number value of 1.2 has been 
selected to switch from non-cavitating to cavitating conditions, according to the experimental data.

\subsection{Inlet and Outlet orifices control logic}

The discharge coefficient calculation is (from GT-Power tutorial) based on the cavitation number. If $K>K_{c r i t}$, there is no cavitation and the discharge coefficient is calculated as:

$$
C_{d}=C_{c} \sqrt{K_{\text {crit }}}
$$

If the cavitation number is less than the critical cavitation number ( $\left.K \leq K_{\text {crit }}\right)$, the orifice is cavitating and the discharge coefficient will be calculated as:

$$
C_{d}=C_{c} \sqrt{K}
$$

where $C_{c}$ is the contraction coefficient, defined as:

$$
C_{c}=\left[\left(\frac{1}{0.61}\right)^{2}-11.4 \cdot \frac{R}{D}\right]^{-0.5}
$$

As the $R / D$ parameter is difficult to determine, an optimization study (DOE varing the rounded corner radius from $0.005 \mathrm{~mm}$ to $0.015 \mathrm{~mm}$ ) was performed in order to correctly model the possible appearance of cavitation.

To evaluate the efficiency degree of the internal GT-Suite logic, the results of two models (with internal control logic and with the implemented control logic) were compared. 
Figure 8 shows the absolute percentage error for the discharge coefficient calculated with GT-Suite internal control (black dashed line), and for the new implemented control logic (dashed line in red) .Looking to the graph, on the Yaxis, $\mathrm{Y} 1$ are the simulated values and $\mathrm{Y} 2$ are the experimental ones, while on

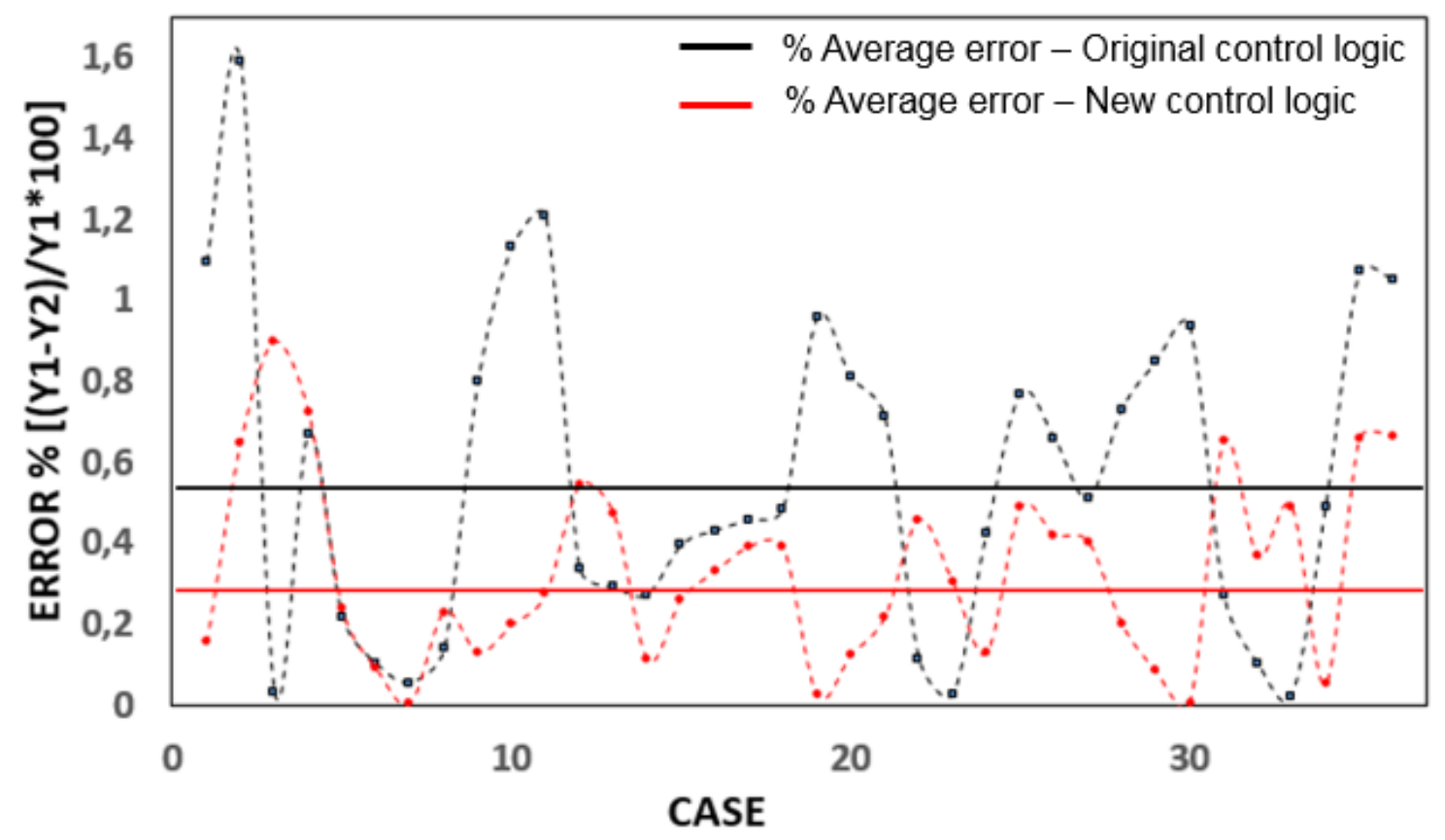

Figure 8.Discharge coefficient error comparison

the $\mathrm{x}$-axis there are the cases, organized for different injection pressures (from the lowest to the highest looking from the left to right) and increasing the back pressure case by case. For almost all the cases the model with the new control logic shows a better match with the experimental values, having an average error of $0.33 \%$ (red continuous line) compared with $0.57 \%$ (black continuous line). GTSuite template overestimates the Cd, resulting in an overestimation of the mass flow rate.

The previously discussed correlations based on equations (6) and (7) are implemented into the $1 \mathrm{D}$ injector model to replicate the discharge coefficient behavior of the control volume orifices. 


\subsection{Nozzle Orifices}

Figure 9 shows the results obtained for the different pressure levels, in term of mass flow vs. the square root of the pressure drop. As it is known from its geometrical characterization, the nozzle orifices have a high degree of conicity, so cavitation is avoided. Consequently, the mass flow linearly increases with the square root of the pressure drop for all the conditions tested.

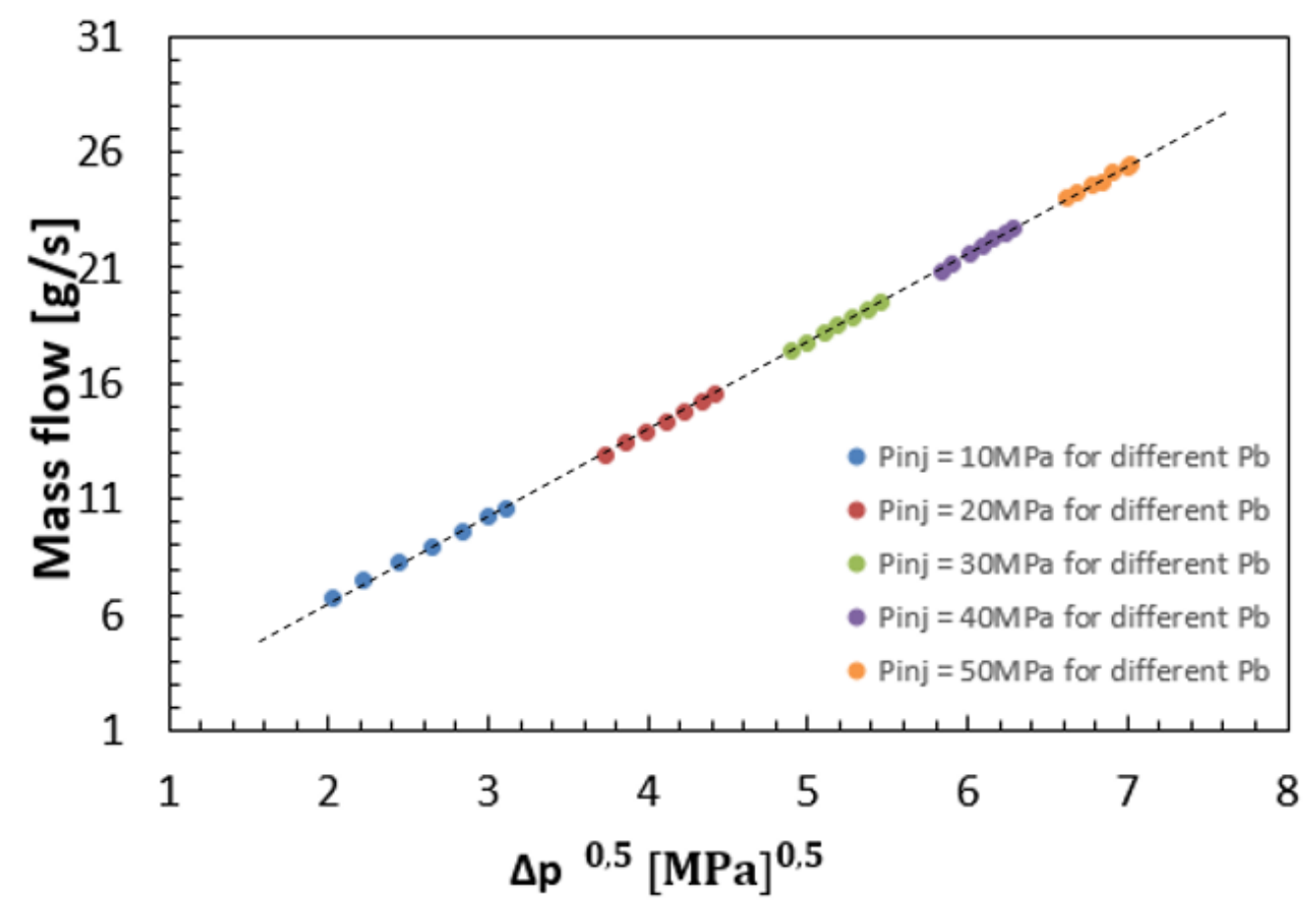

Figure 9. Steady-state mass flow for nozzle orifices

As it was previously discussed for the control volume orifice, a correlation based on equation (6) has been obtained to reproduce the discharge coefficient behavior in the 1D-model. In this case, the obtained values of $C_{d, \max }$ and $A$ are 0.898 and 8.82 , respectively, resulting in a R-squared value of $98.4 \%$. 


\section{Model validation}

In this section, the 1D injector model will be validated against the injection rate experimental data for both single and multiple injection strategies.

\subsection{Single injections}

In order to validate the model under a single injection strategy, two different approaches have been adopted. For the first, a constant pressure, equal to the nominal value has been used as input for the model, while the pressure time evolution recorded during the experimental campaign has been chosen for the second approach. In the following subsections, we present the results of the two different methods and the relative comparison.

\subsubsection{Constant inlet pressure}

As first approach the inlet pressure at the rail element has been imposed equal to the nominal value. Figure 10 shows the injection rate curves for a case with low pressure $\left(P_{i n j}=30 \mathrm{MPa}\right)$, backpressure equal to $5 \mathrm{MPa}$ and 4 energizing time values $(0.2,0.3,0.4$ and $1 \mathrm{~ms})$. In general terms, the model is able to reproduce the main features of the injection rate profile, including the injector opening and closing events. The only exception is in the $0.2 \mathrm{~ms}$ case, where the model is having a clear overestimation of the total injected quantity. Nevertheless, it has to be considered that the injection operation under such low injection pressure and duration is quite unstable. Indeed, the coefficient of variance observed in the experimental tests at these conditions is over $45 \%$. Such unstable operation cannot be reproduced by the 1D model, which explains the higher deviation observed. 


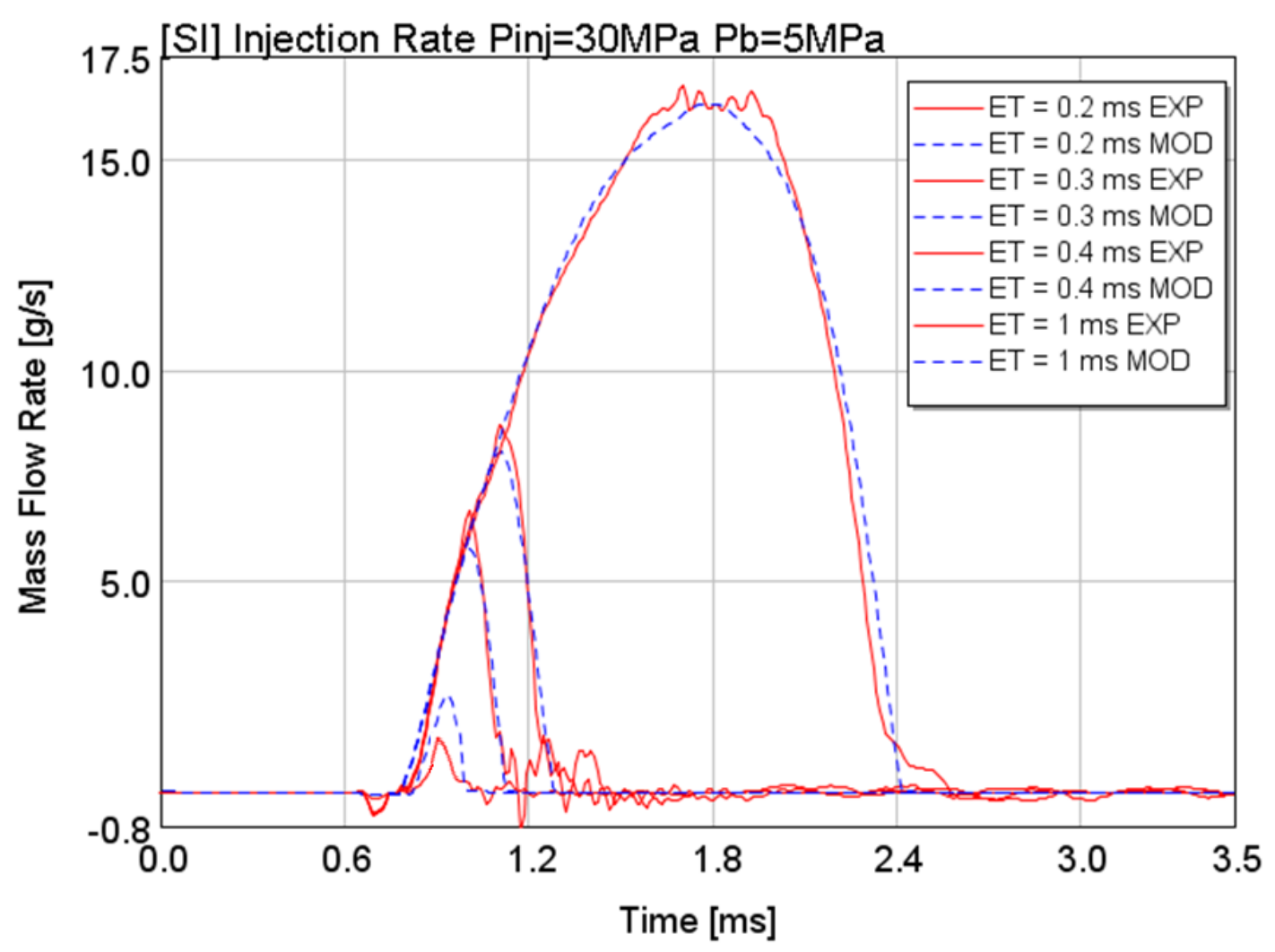

Figure 10. Modelled vs. experimental injection rate for different ETs. $P_{i n j}=30 \mathrm{MPa}, P_{b}=5 \mathrm{MPa}$

A similar comparison has been performed for the highest injection pressure $P_{i n j}=180 \mathrm{MPa}$ (Figure 11). Again, the model is able to reproduce in a reasonable way the experimental profiles, with a slight overestimation of the maximum injection rate. This overestimation is linked to the discharge coefficient equation presented in section 4.2 for the nozzle orifices, which also tends to overestimate the experimental permeability tests in the high Reynolds number area. It is important to note that when the injection is over, the signals do not recover the initial zero showing an unreal mass flow rate value. This phenomenon is caused by the pressure waves propagation in the ROI meter after the needle closure, and increases as the injected mass increase (higher injection pressure and energizing time). Hence, the tail area at the end of injection is not real, and the 1D injector model does not have to try to reproduce it. 


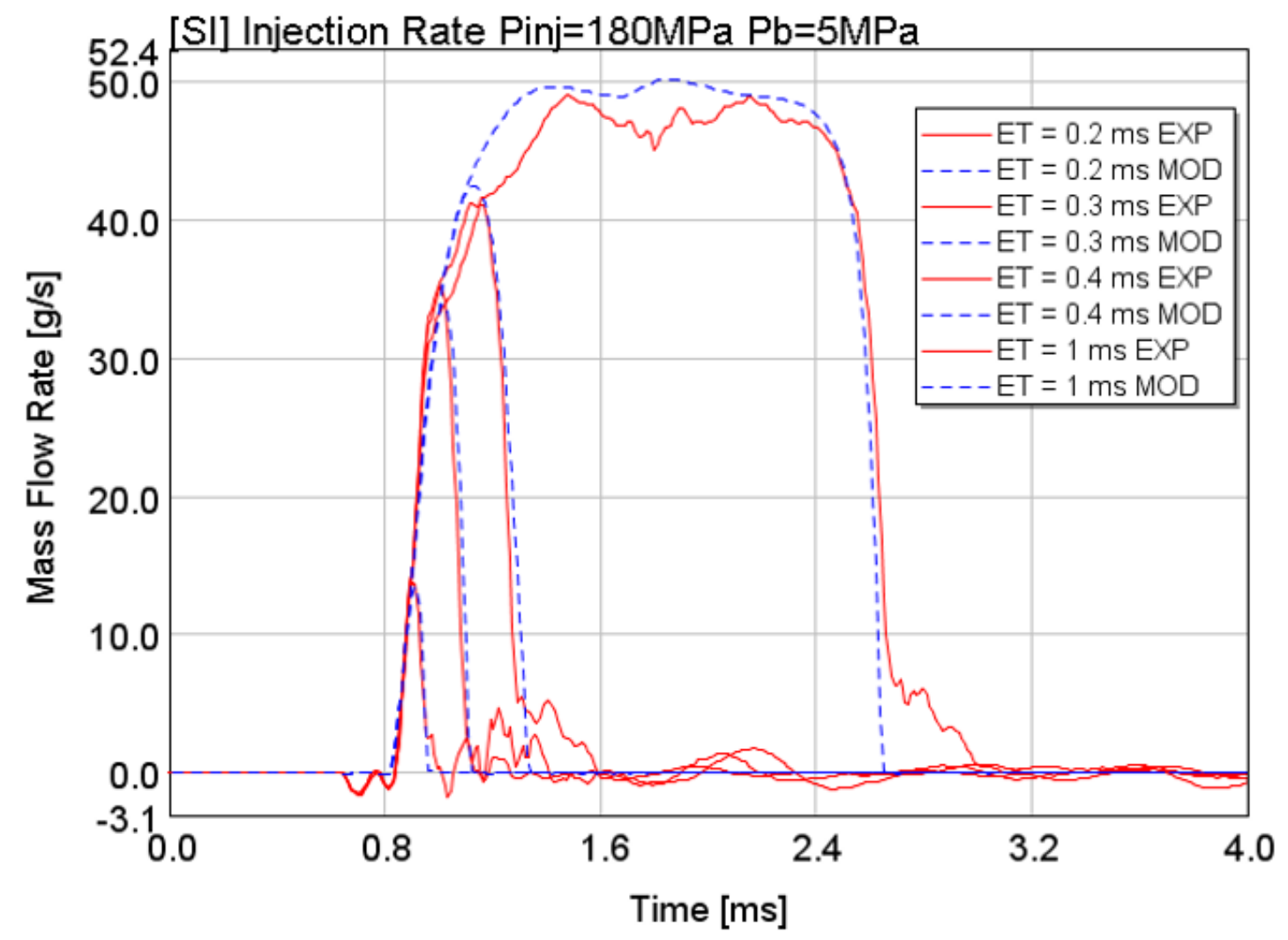

Figure 11. Modelled vs. experimental injection rate for different ETs. Pinj $=100 \mathrm{MPa}, P b=5 \mathrm{MPa}$

\subsubsection{Variable inlet pressure}

In order to better model the upper part of the injection rate regarding the large injection events $(E T=1 \mathrm{~ms})$, the high-pressure pump and the high pressure line upstream the common rail have to be modelled as well. This solution would require a lot of efforts, so a good approximation that take into account the pressure oscillations generated by the injection system can be the implementation of the pressure time evolution instead of the constant pressure value [41]. Figure 12.a shows a typical pressure time evolution during the single injection event. Hence, a better fit in the stationary part of the injection rate 
,compared with the first approach curve, can be obtained without losing accuracy in the opening and closing phases as expected (Figure 12.b).
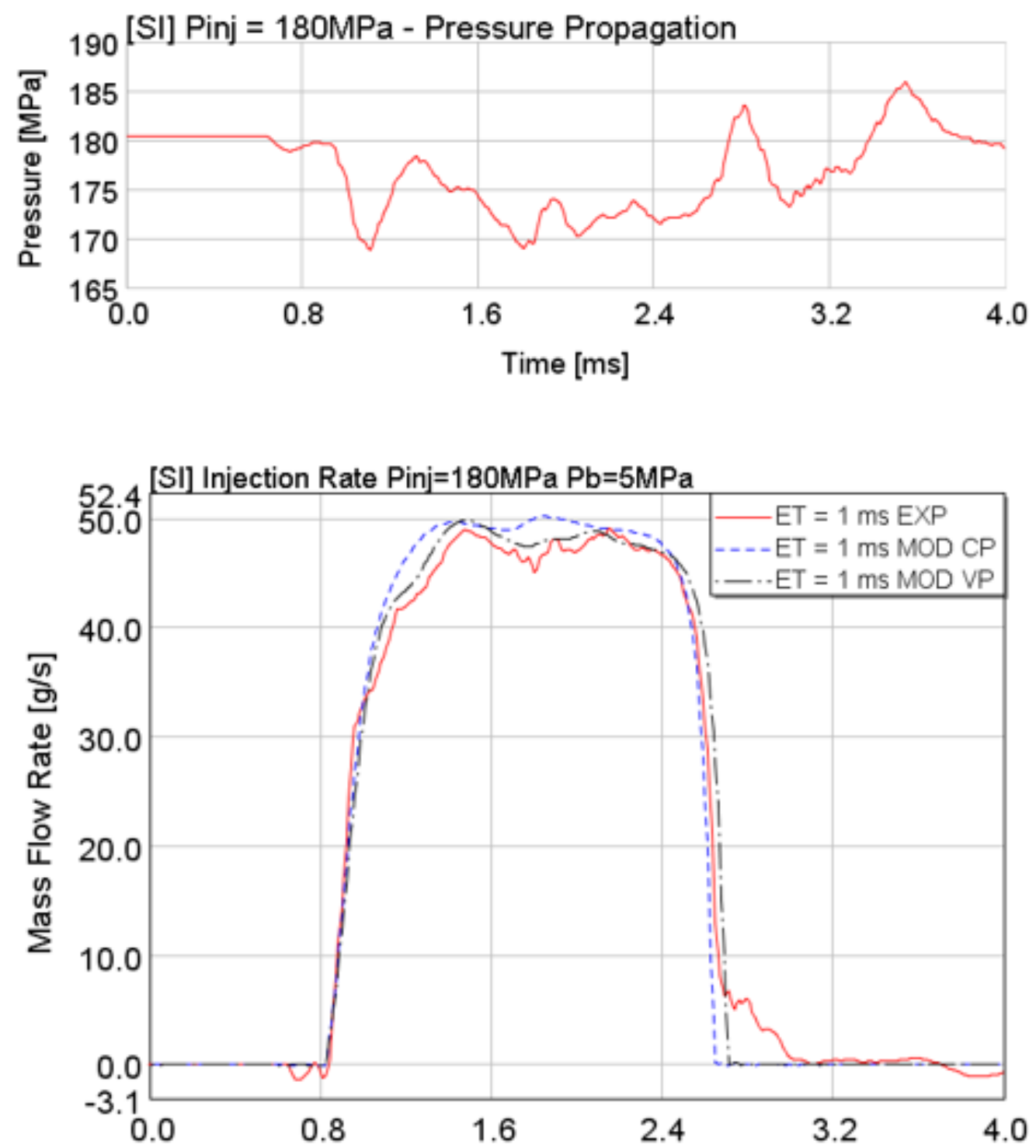

Figure 12. a. Experimental vs modelled rail pressure evolution (Pinj=180MPa) b. Injection rate comparison with constant rail pressure in blue and variable pressure evolution in black

On the other hand, the main purpose of the work is to provide independence from the experimental conditions from which the model has been validated, enabling it to work in a wider range of inlet conditions. For this reason, a constant pressure value in the rail element was maintained. 


\subsubsection{Total Injected mass}

Finally, the modeled total injected mass has been compared with the experimental one in Figure 13 for all the conditions tested. Generally there is a very good correlation between the experimental and modelled values, as it can be seen from the high R-squared value (99.77\%). The correlation is significantly good even for small masses (that represent part-load engine conditions) showing an R-squared value(96.06\%), where few points have a significant deviation with respect to the experimental values, as it can be seen in the zoomed area.

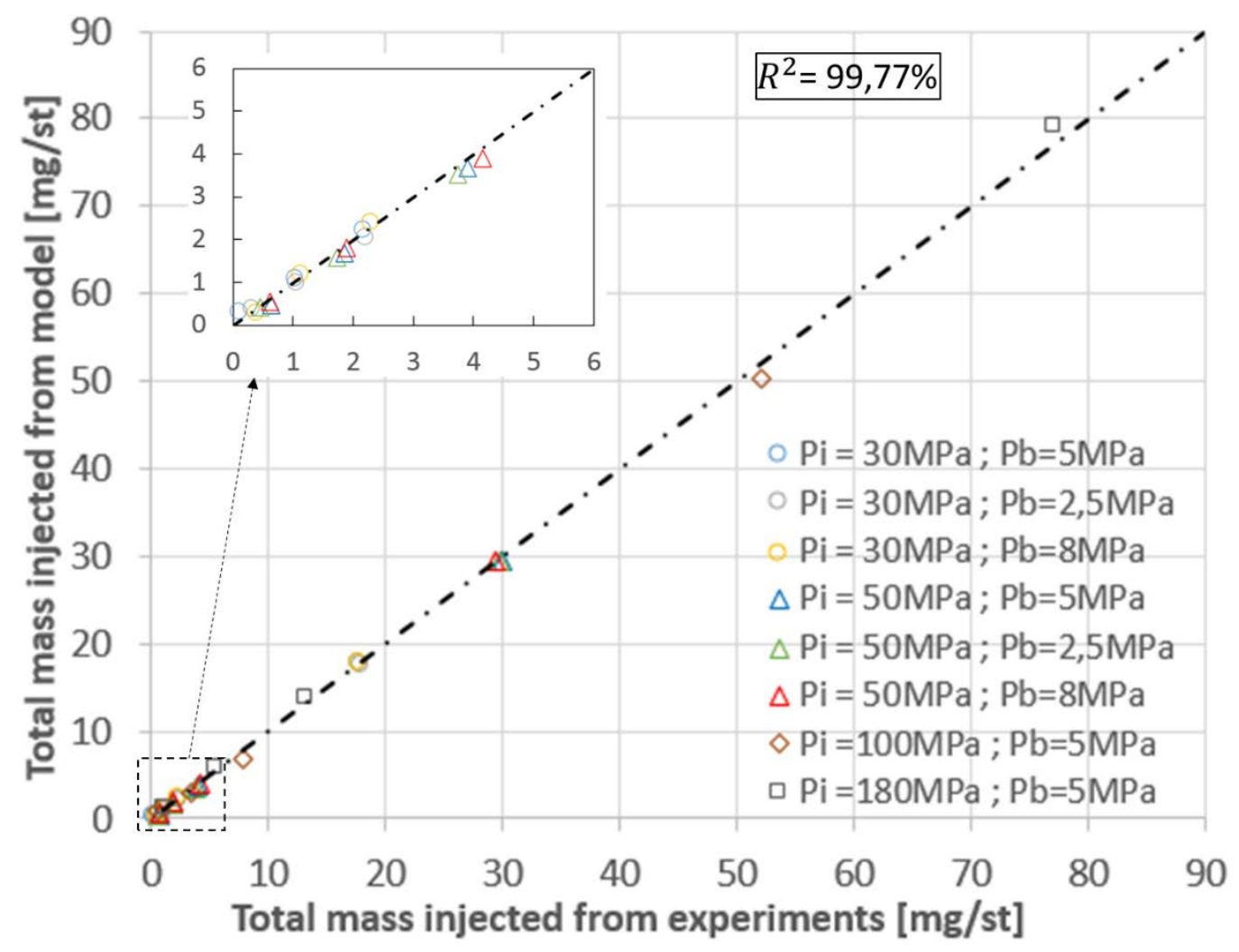

Figure 13. Modelled vs. experimental total injected mass for single injections 


\subsection{Multiple injections}

Figure 14 shows the experimental vs. modeled injection rate for a pilot+main injection strategy. This particular condition is characterized by a low pressure value $\left(P_{i n j}=30 \mathrm{MPa}\right)$, with the energizing time of the first injection ET1 $=0.2 \mathrm{~ms}$, the energizing time of the second injection $\mathrm{ET} 2=0.4 \mathrm{~ms}$, evaluated for 3 different dwell times: $0.15,0.5$ and $0.8 \mathrm{~ms}$. In all cases, the first injection is overestimated, as it was already seen for the single injection strategy at the same conditions. This overestimation leads to a merge of the two injection events in the particular case of $\mathrm{DT}=0.15 \mathrm{~ms}$, which does not appear in the experimental profiles. Nevertheless, the overall profile of the second injection is well reproduced even at this close-coupled condition. For the other two dwell times, the opening point of the second injection is accurately captured, while higher differences are observed in the absolute values of the maximum injection rate and the hydraulic duration, although the trends are similar between experiments and simulations.

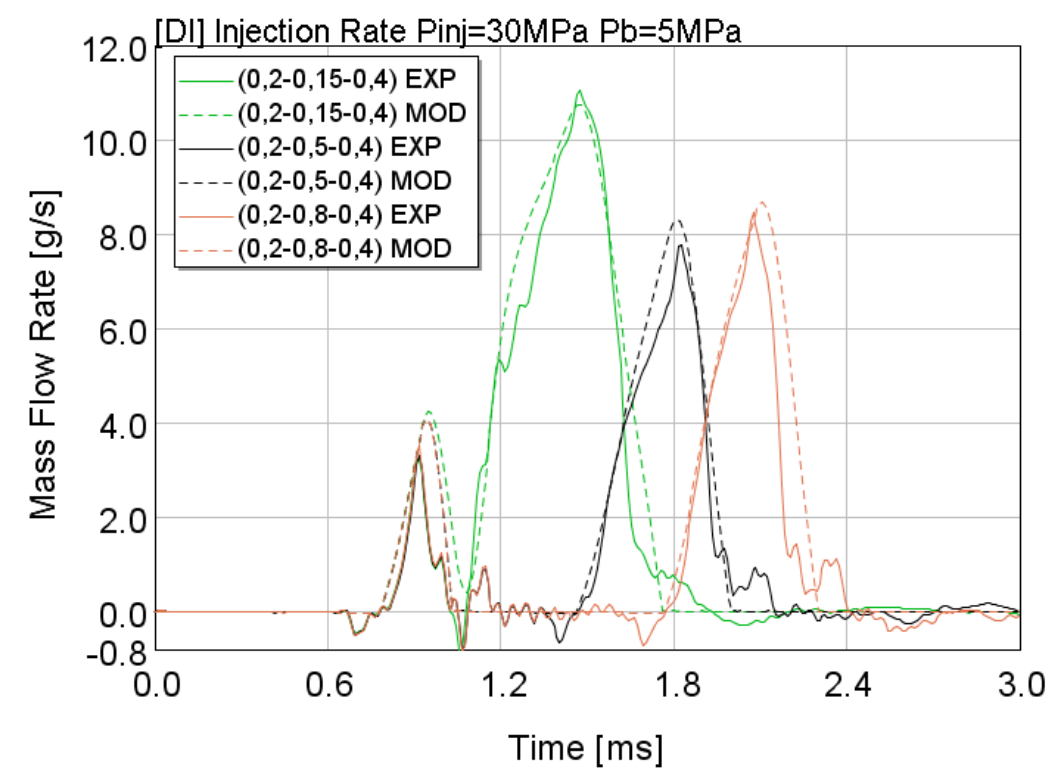

Figure 14. Modelled vs. experimental injection rate for pilot+main strategy at different dwell times. $P_{\text {inj }}=30 \mathrm{MPa}$ 
Figure 15 shows a similar analysis but for the 100MPa case. Under these conditions, the pilot injection quantity and duration is better reproduced, and as a consequence the opening point of the second injection on the model is more representative of the real operation of the injector. Additionally, the model is more accurate in reproducing the second injection rate shape characteristics compared to the $30 \mathrm{MPa}$ case previously analyzed.

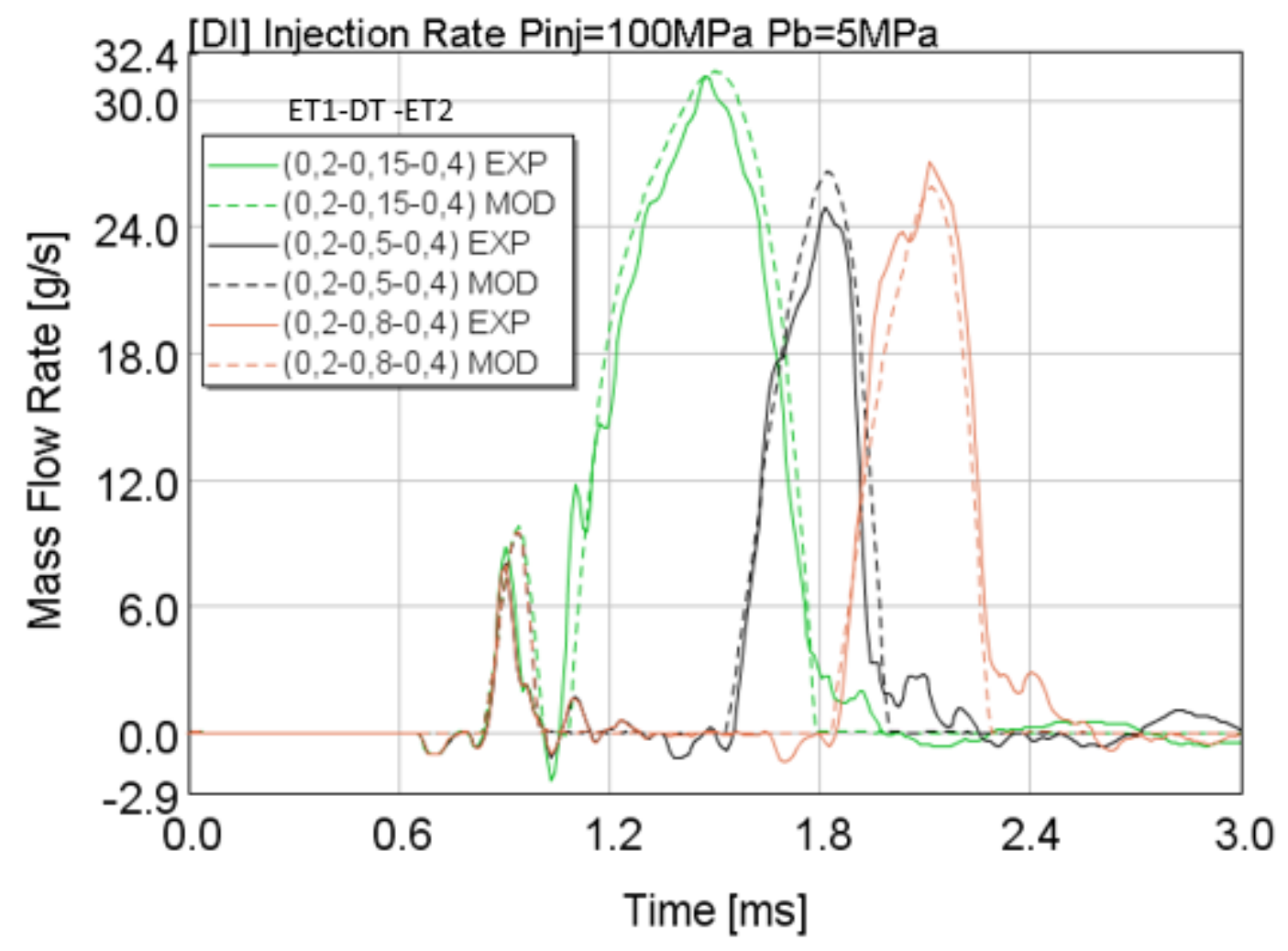

Figure 15. Modelled vs. experimental injection rate for pilot+main strategy at different dwell times. $P_{\text {inj }}=100 \mathrm{MPa}$ 
Figure 16 compares the experimental vs. modelled opening times for the second injection in all the multiple injection cases. For this comparison, the cases in which there was a hydraulic merge of the two injections in either the experimental or the modelled data were not considered. Again, the fidelity of the model is very high, as it can be seen also from the R-squared value of $99.24 \%$.

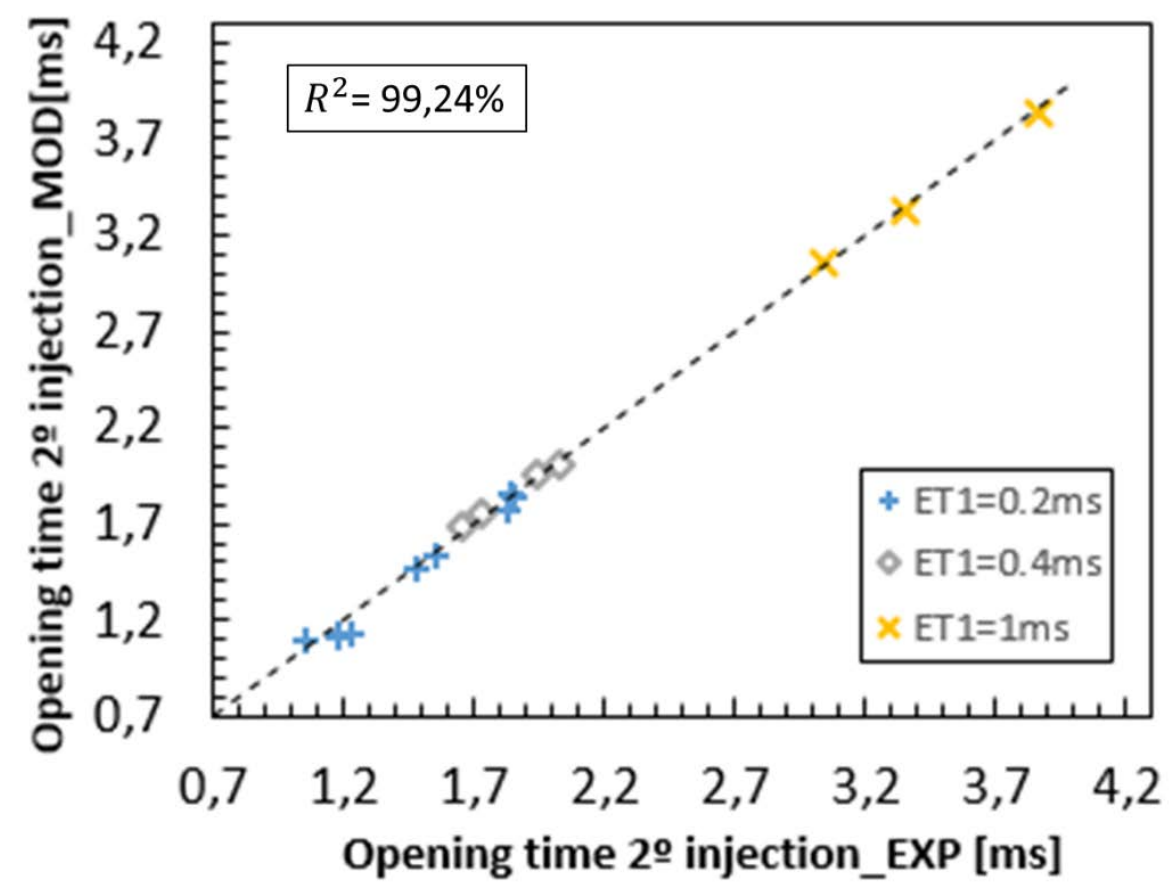

Figure 16. Experimental vs modelled opening time for the second injection

Then, an other parameter analyzed is the total injected quantity under multiple injections. The results are seen in Figure 17. Although the differences in total quantity are higher compared to those already analyzed for the single injection case (Figure 13), for most of the conditions the agreement is still acceptable levels. In fact, the two sets of values show a high statistical correlation according to the calculated R-squared value of $99.62 \%$. Once again, the part-load engine 
area has been evaluated, resulting in a R-squared value of $85.30 \%$ for cases with injected mass less than $13 \mathrm{mg}$. It is important to point out that the injected mass value comes from the integral of the mass flow rate curve and does not take into account the instantaneous error.

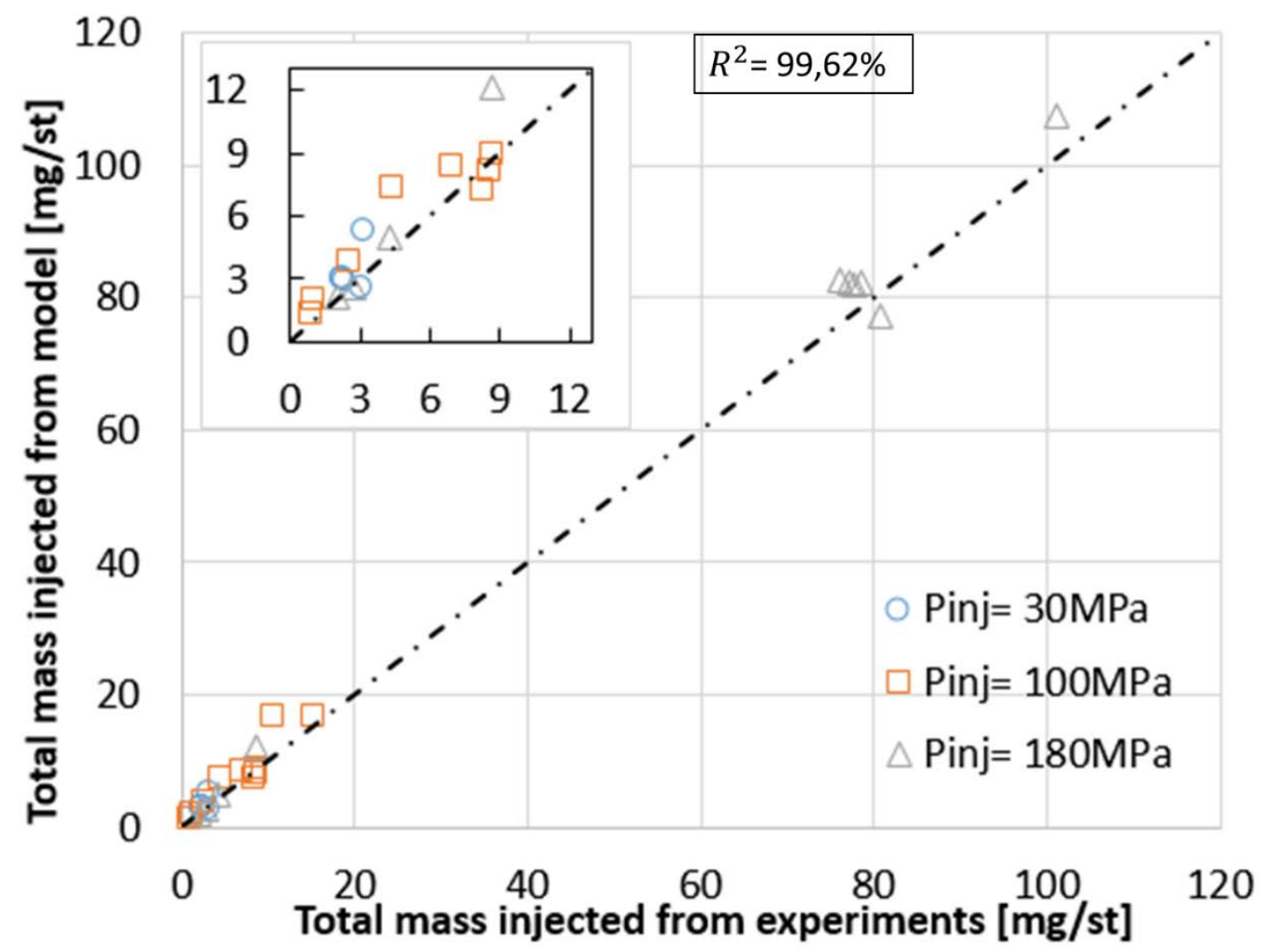

Figure 17. Modelled vs. experimental total injected quantity for multiple injection strategies

Finally, the last parameter of interest for the model validation is the evaluation of the injected mass during the second injection respect to the total amount of mass, varing the dwell time $(0.15 \mathrm{~ms}<D T<0.8 \mathrm{~ms})$. Figure18 refers to a case with injection pressure equal to $100 \mathrm{MPa}$, backpressure of 5MPa, and same energizing time for the first and second injection event $(E T=0.2 \mathrm{~ms})$. At relatively low $D T$ values (between 0.15 and $0.45 \mathrm{~ms}$ ), the second mass injected is clearly affected from the $D T$. As $D T$ increases, both experimental and simulated data converge to a value of 0.5 , which means that the mass injected during the second event is 
not dependent from the $D T$. Indeed, the amount of mass injected is the same for the two injections. Overall, for all $D T$ range tested, the model is capable of reproducing the trend seen experimentally with acceptable accuracy even if it operates with critical boundary conditions (smaller energizing time, resulting in small amount of injected mass). More details about the topic will be provided in the next sections.

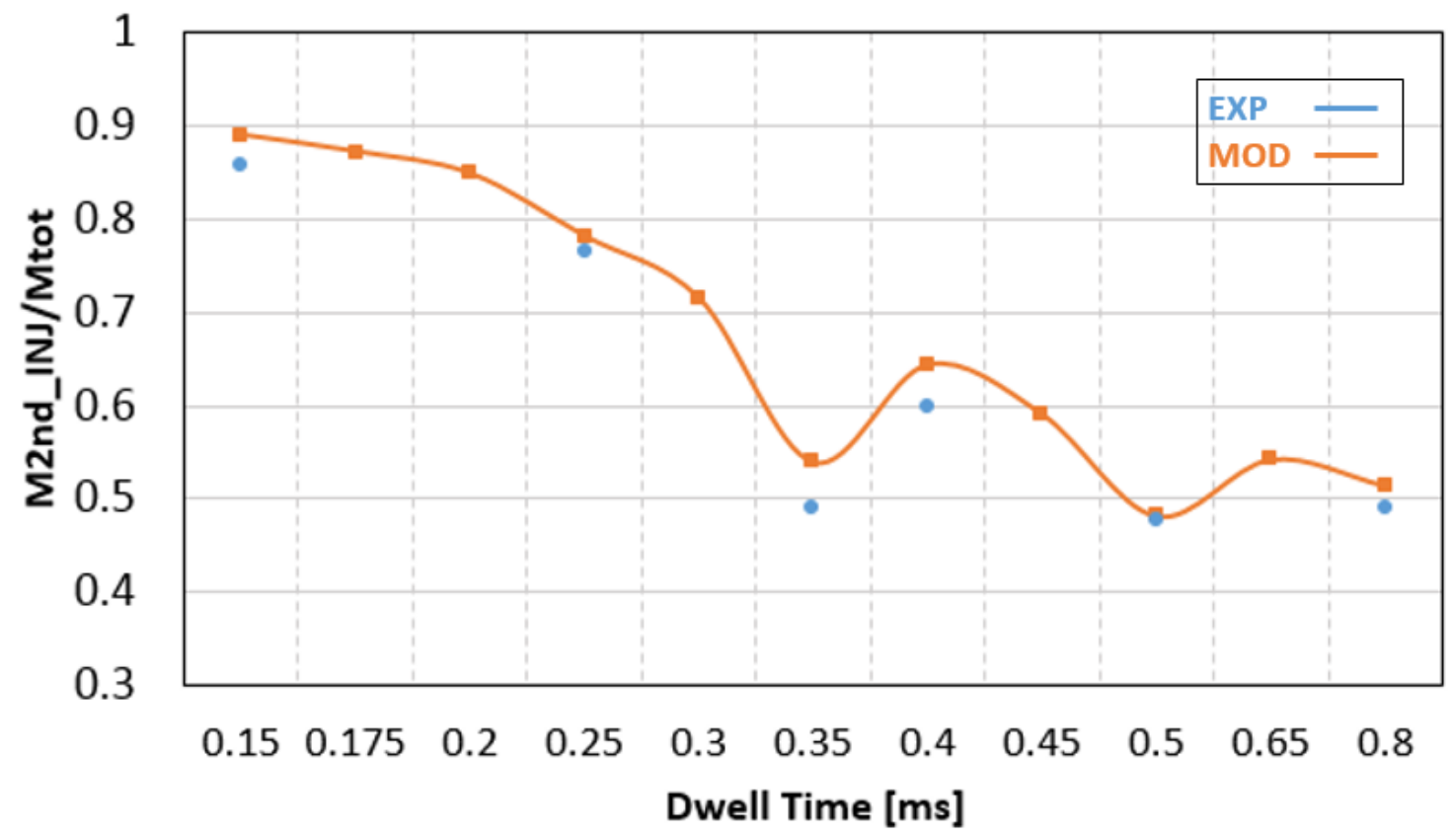

Figure 18. Second injected mass weight respect to the total injected mass vs Dwell Time. Test condition: Pinj=100MPa, ET1=0.2ms, ET2=0.2ms. 


\section{Interaction between close-coupled injections}

Once the calibration of the model was complete, the model was used to formulate hypotheses on what happens when the injection events happen in close succession. The model could not capture all the details of multiple injection, but it possessed the necessary physical characteristics to help explain most of the injector behaviors. These hypotheses were not proved experimentally, something that is addressed in section 8 .

In this section, a detailed analysis of the hydraulic interaction between injections is performed. Three parameters are considered: the second injection mass, the critical dwell time (defined as the minimum $D T$ to achieve complete hydraulic separation between injections) and the initial slope of the injection rate.

\subsection{Critical Dwell Time}

The critical dwell time can be defined as the minimum electrical separation between injections needed to obtain two separate injection events from a hydraulic standpoint. For a given fuel injection system, shorter critical dwell times are an indication of faster injector dynamics and higher possibility to perform compact injection strategies, which have shown some potential advantages for controlling combustion noise and NOx emissions [39].

The model has shown that it is able to reproduce the second injection opening event with high accuracy (see fig.16). Therefore the model was used to assess the critical dwell time by increasing energizing time of the first injection from 0.2 to $1 \mathrm{~ms}$ (step increment of $0.1 \mathrm{~ms}$ ), for three injection pressure levels. Figure 19 
shows the information of the critical dwell time as a function of the energizing time of the first injection and the injection pressure.

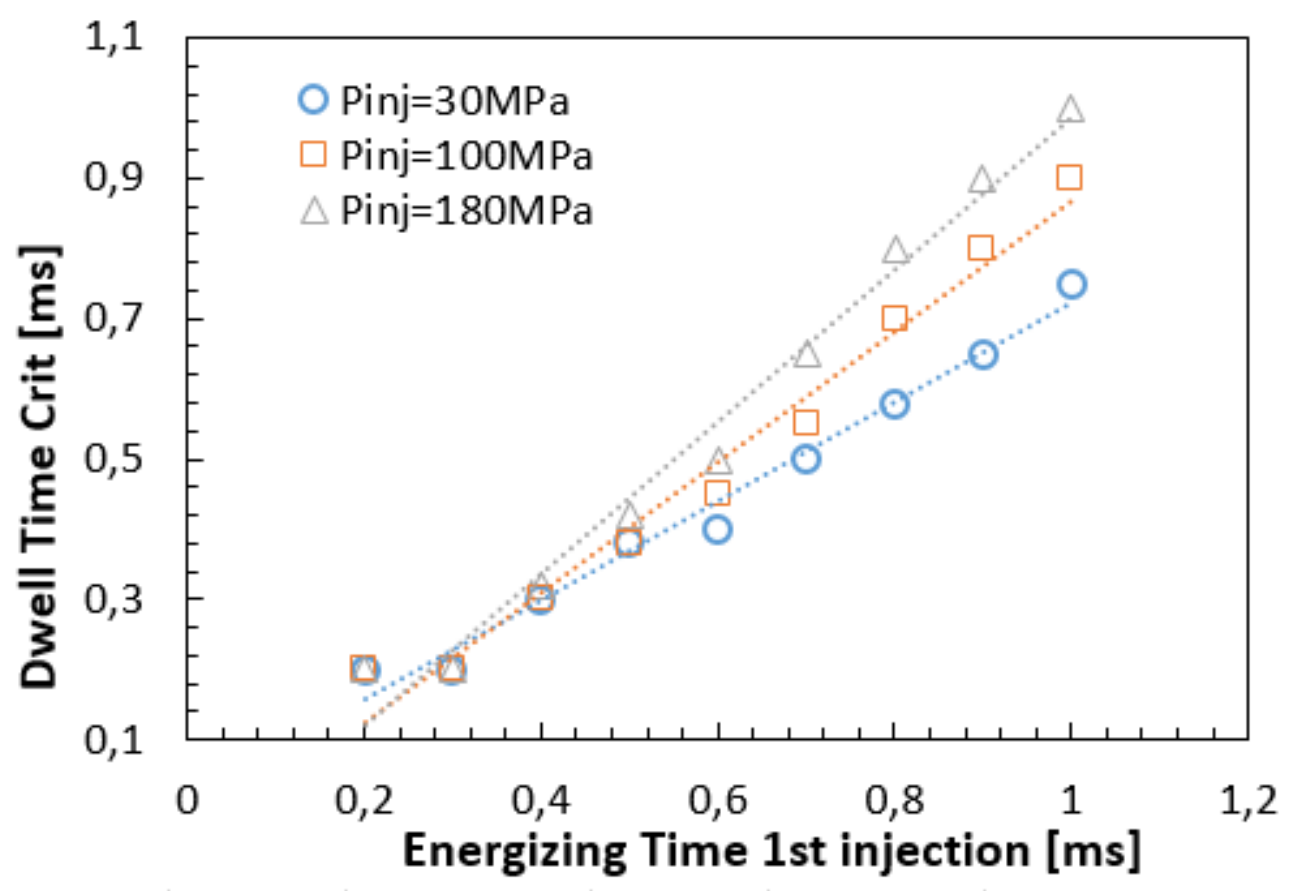

Figure 19. Simulated Critical dwell time as a function of ET1 and Pinj

The different symbols show the characteristic critical dwell times obtained in the model for different injection pressures and energizing time for the first injection. In general, increasing the value of ET1 tends to increase also the critical dwell time with an approximately linear trend, which is represented by the dashed lines. Additionally, it can be observed that the slope increases with the injection pressure. This is due to the fact that, for the same energizing time, a higher rail pressure results in a longer hydraulic duration of the first injection. Nevertheless, this behavior disappears when the value of $E T 1$ is equal or lower than $0.3 \mathrm{~ms}$, for which the critical $D T$ remains approximately constant at $0.2 \mathrm{~ms}$, independently on the particular values of ET1 and $P_{i n j}$. It is important to remember that this trend should be confirmed with more experimental cases. A possible explanation could 
be found by analyzing the delay between the end of the electrical signal and the closing of the control valve, that is approximately $0.15 \mathrm{~ms}$, as pointed out in Figure 20 , limiting the minimum critical dwell time achievable at any condition.

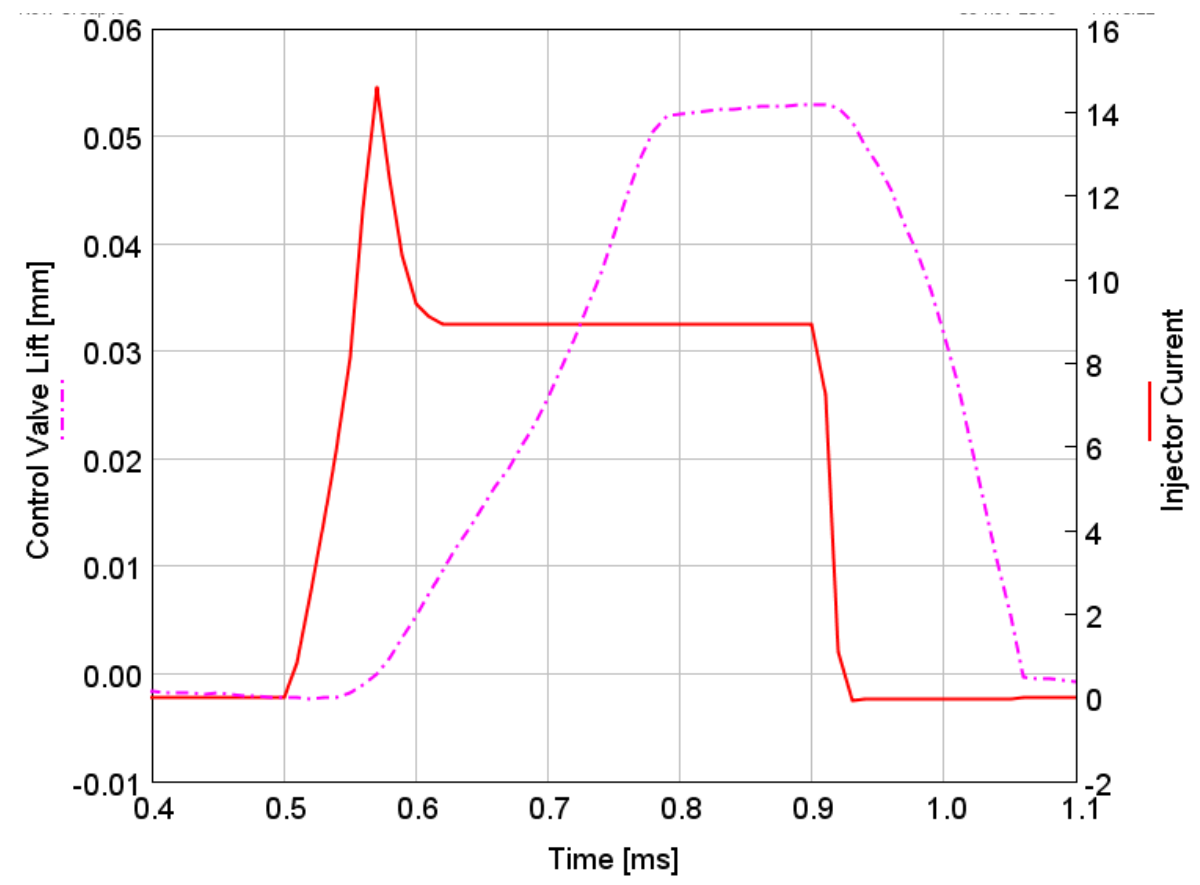

Figure 20. Simulated electrical current and control valve lift

The purpose of the following analysis is to find the technological limits of the injector and how it works close to these conditions, in order to avoid potentially unstable modes of operation. When the injector works under condition of DT<DTcrit the two injection events overlap, resulting in unstable combustion phenomenon. 


\subsection{Effect on the second injection mass}

One of the most important aspects when using close-coupled multiple injection strategies is the effect that the first injection has on the mass injected during the second one. This can be seen in Figure 21 for a particular case of $P_{\text {inj }}=100 \mathrm{MPa}$ and same energizing time for the first and the second injection ( $E T=0.4 \mathrm{~ms})$. In this figure, the horizontal continuous line represents the value of the mass injected with the same boundary conditions on a single-injection case, while the dashed lines represent the time evolution of the second injected mass. The values are represented against the electrical dwell time between the injections. Conditions with dwell time lower than the critical have been excluded.

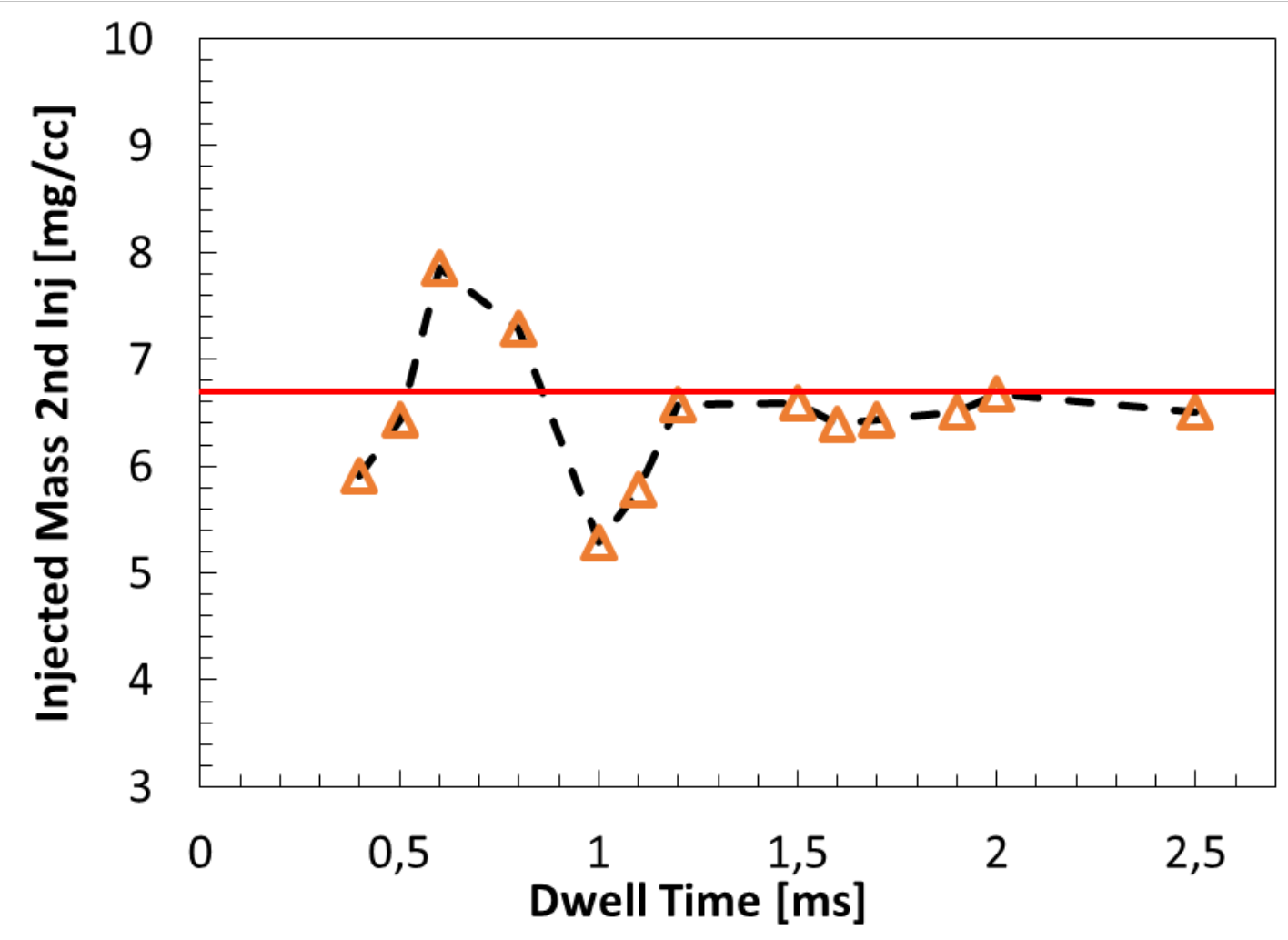

Figure 21. Simulated results of second injection mass on a split injection for $P_{i n j}=100 \mathrm{MPa}$, $E T 1=0.4 m s, E T 2=0.4 m s$

At relatively low $D T$ values (between 0.4 and $1.2 \mathrm{~ms}$ ), there is a clear dependence of the dwell time on the second injection mass. The maximum deviation of this 
mass compared to the first injection is approximately $16 \%$. Additionally, the trend observed is not monotonic, but the second injection mass may be higher or lower than the value expected from the single injection case depending on the specific dwell time used. When the $D T$ is higher than $1.2 \mathrm{~ms}$, the second injection mass becomes almost constant, and very similar to the value predicted through the single injection case. Similar behavior has been observed for other values of ET1 and $P_{i n j}$.

Due to the cyclical/wave nature of figure 21, pressure wave propagation generated during the first injection event could be the prime suspect. But reader should remind that this is a 1-D model and some other underlying phenomena or their extent might have not been accurately captured. For any multiple injection case, the propagation of this pressure wave affects the pressure conditions inside the injector, and in particular in the control volume and the needle seat region, impacting the boundary conditions for the needle and piston rod movement. 

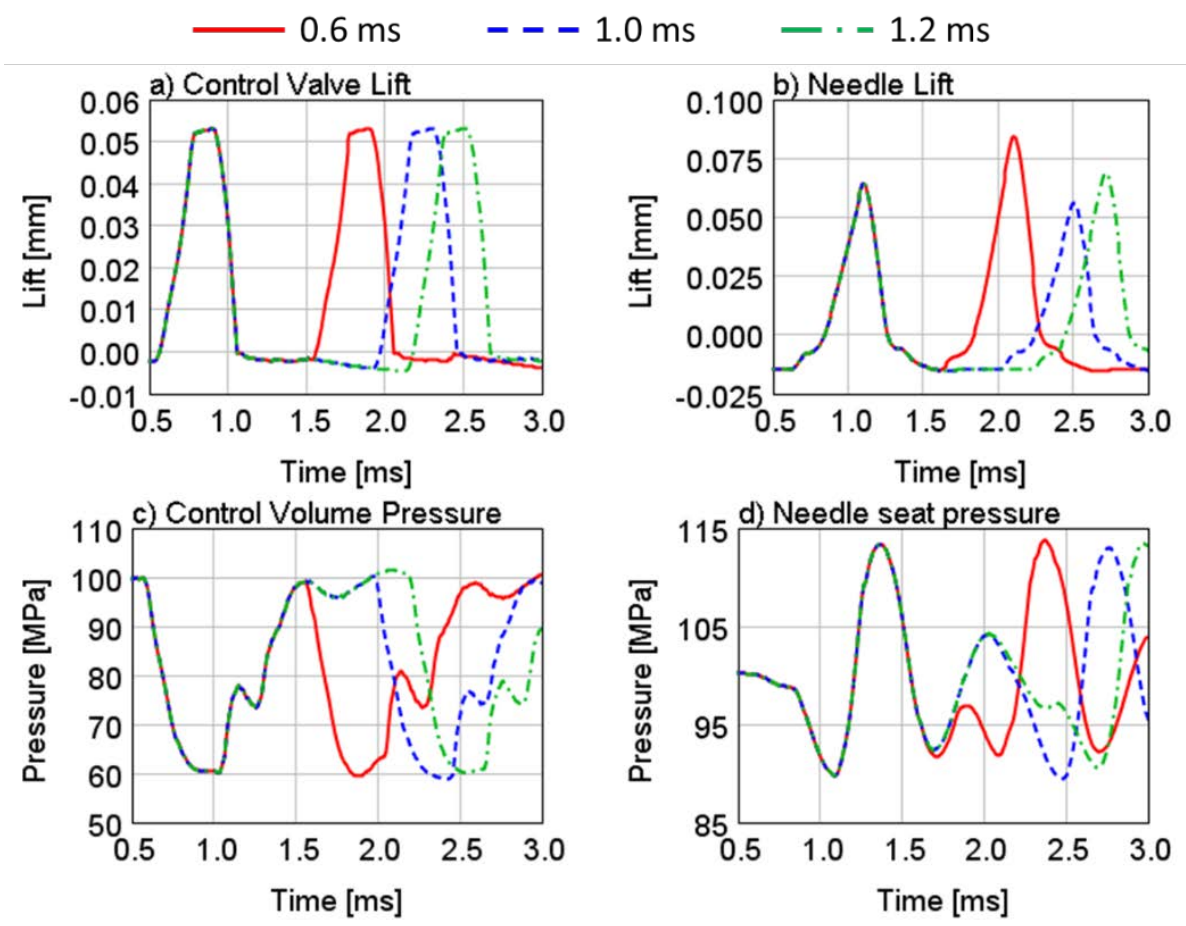

Figure 22. Simulated results of control valve and needle dynamics for Pinj=100 MPa, $E T 1=E T 2=0.4 \mathrm{~ms}$ and $D T=0.6,1$ and $1.2 \mathrm{~ms}$

Figure 22 shows the information of the control valve lift (a), the needle lift (b), the control volume pressure (c) and the needle seat pressure (d) for the same injection strategy analyzed in Figure 21. In particular, three different DT values are shown: $0.6 \mathrm{~ms}$ (corresponding to the maximum second injection mass), $1 \mathrm{~ms}$ (corresponding to the minimum) and $1.2 \mathrm{~ms}$. For this particular case, it can be seen that the control volume pressure during the control valve opening is very similar for all three cases. Nevertheless, significant differences can be found in the needle seat pressure dynamics, which result in the $0.6 \mathrm{~ms}$ case reaching a higher maximum needle lift and a consequently a higher second injection mass.

\subsection{Effect on opening slope}


Figure 23 shows the initial slope of the needle lift profile for the first injection (empty symbols) and second injection (filled symbols) at the critical dwell time conditions as a function of the energizing time of the first injection. This opening slope is characterized by the time needed to reach a needle lift of $0.015 \mathrm{~mm}$, starting from the first positive value of needle lift (that means after the elements deformation has been recovered). As expected, this time significantly reduces as the injection pressure increases, due to the higher pressure forces acting on the needle and the piston rod, together with the higher velocities reached in the OA orifice. Additionally, the opening slope is steeper for the second injection compared to the first one. This is a result of two compound effects: on the one hand, at the critical dwell time condition the needle and piston rod have not recovered their initial deformation yet; on the other hand, the control volume and needle seat pressure conditions are different from the single injection cases, as already discussed in section 6.1 .



Figure 23. Simulated results of time for $0.015 \mathrm{~mm}$ needle lift as a function of ET1 and Pinj For most of the cases modelled, it can be seen that the initial slope of the needle lift profile at the critical dwell time is approximately independent from the duration 
of the first injection. Nevertheless, in the case of the second injection and $P_{i n j}=$ $30 \mathrm{MPa}$, a different behavior appears. In particular, it can be seen that at low ET1 values, increasing the first injection duration results in an increase of the time needed to reach $0.015 \mathrm{~mm}$ lift. At ET1=0.6 ms the trend inverts, until reaching a constant value of approximately $0.092 \mathrm{~ms}$ for ET1>0.8 ms.

In order to better understand this behavior, the pressure decrease gradient (in $\mathrm{MPa} / \mathrm{ms}$ ) has been plotted against the injection pressure for the specific ET1 values of $0.3,0.6$ and $0.9 \mathrm{~ms}$. As it can be seen, for the injection pressure cases of 100 and $180 \mathrm{MPa}$, this pressure gradient is almost equal for all the energizing time conditions. This is consistent with the fact that the time needed for the 0.015 $\mathrm{mm}$ lift does not depend on ET1. On the contrary, the pressure gradient in the control volume is highly dependent on the first injection duration for the $30 \mathrm{MPa}$ cases, inducing the behavior previously observed.

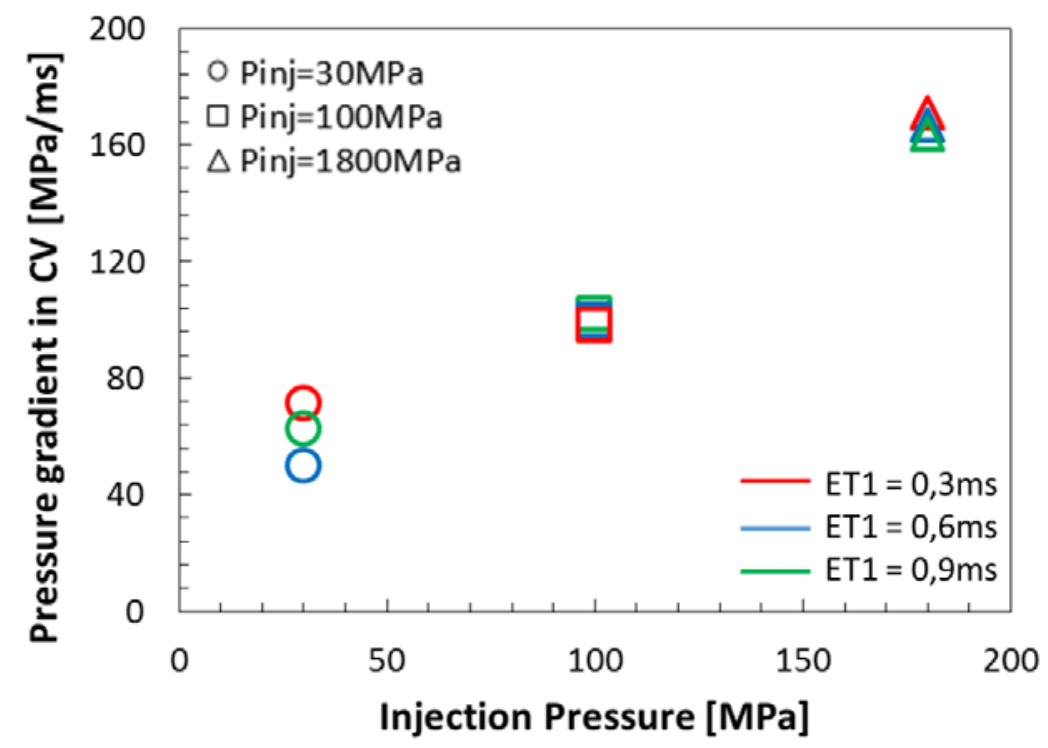

Figure 24. Simulated results of pressure gradient decrease in the control volume at the control valve open

\section{Conclusions}


In the current paper, a one-dimensional model of a solenoid fuel injector has been used to evaluate the hydraulic interactions between close-coupled injection events. First, the internal elements of the injector have been geometrically and hydraulically characterized, in order to obtain the necessary information to construct the model. Particularly, a detailed characterization of the main orifices inside the injector (control volume inlet, outlet and nozzle outlet) has been carried out. The 1D model has been then adjusted and validated against a set of injection rate measurements, including both single and multiple injection cases. For most of the conditions, the model has shown good capability to reproduce the experimental hydraulic delay, injection duration and total injected mass.

Once the model was finalized, it has been extensively used under close-coupled injection conditions to propose hypotheses explaining some of the phenomena happening within the injector. The following conclusions have been found:

- The critical dwell time, defined as the minimum electrical separation needed to produce two separate injection events, tends to increase as ET1 and $P_{i n j}$ get higher, due to the longer hydraulic duration of the first injection.

- The minimum dwell time achievable with the particular hardware used for the study is approximately $0.2 \mathrm{~ms}$, independently on the injection pressure. This value is mostly limited by the dynamic behavior of the control valve.

- The mass of the second injection is significantly affected by the first injection conditions at mid-to-low dwell time conditions, with deviations in the second injection mass up to $16 \%$ compared to a single injection strategy. This behavior is due to the pressure dynamics inside the injector, mostly on the needle seat region. 
- When running the injector at the critical dwell time, the opening slope of the needle lift profile is generally faster for the second injection event. This is due to the combination of a smaller initial deformation of the needle and piston rod elements, and the different pressure boundary conditions inside the injector. The effect on the needle opening is significantly depending on the first injection duration for low injection pressure $\left(P_{i n j}=30 \mathrm{MPa}\right)$, while is almost constant for higher injection pressure values.

\section{Suggestions for further improvement}

An injector model has multiple uses have different requirements on accuracy and fidelity. For example, for a hydraulics injection study where the scope is finding natural frequencies of the injection system the requirements are different if the model is used as an input to a combustion model. For the latter case, apart from total injected quantity accuracy, the timing and instantaneous rate shape fidelity are of equal importance since discrepancies in the injection modeling effort would be inherited into the combustion modeling effort. Some suggestions for further improvement in this study are listed below:

1. Measurement of needle/ armature springs on a force-displacement apparatus

2. Rerun the ROI measurements in finer detail for the closed coupled injections to confirm the conclusions in this study which were model based. 3. The method available in the experimental measurement can be classified as 
A. Steady state - hydraulic characterization of the critical orifices and nozzle, geometrical measurements of the injector components and silicone moulds, material properties and mechanical properties B. Transient - Rate of injection measurement (ROI)

Currently, these two types of measurements leave a large "gap" for the 1D model to bridge between especially in the highly dynamic condition of closed coupled injections were engine operates in real world conditions. Further improvement to the method would arise if the measurement is available inside the injector during the transient. An instrumented injector would help distinguish if a particular behavior is, for instance, hydraulic or mechanical and the model parameters finetuned accordingly. Currently, the transient phenomena inside the injector are indistinguishable and therefore the calibration of the 1D model very hypothetical in nature. This problem description is depicted graphically below:

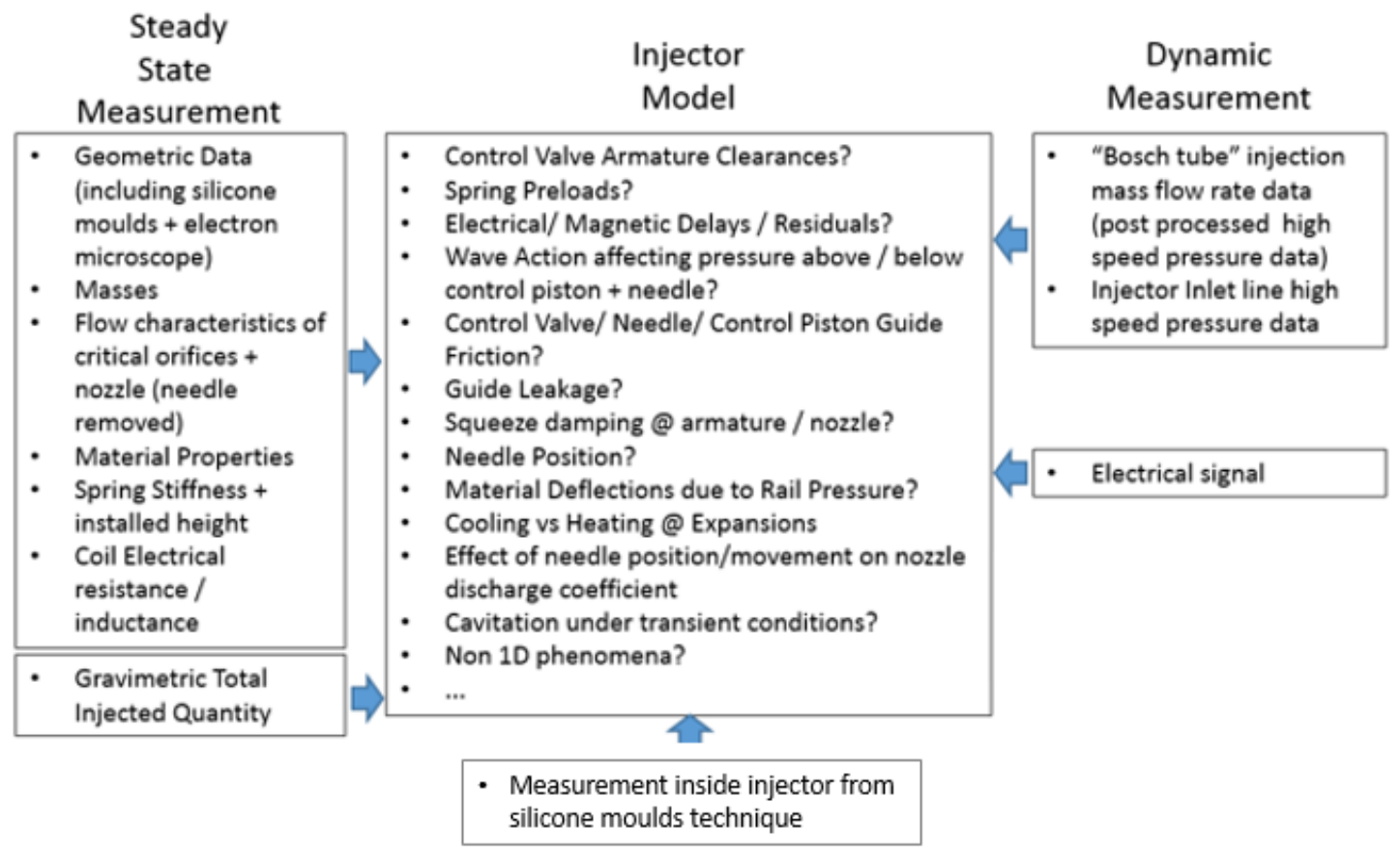

Figure 25.1D injector model scheme 


\section{ACKNOWLEDGMENTS}

The authors would like to thank Mr. Jose Enrique del Rey and Mr. Jorge Navarro for their collaboration during the injector geometrical and hydraulic characterization activities.

\section{REFERENCES}

[1] T. V. Johnson, "Vehicular Emissions in Review," SAE Int. J. Engines, vol. 5, no. 2, pp. 2012-01-0368, 2012.

[2] I. A. Khalek, M. G. Blanks, P. M. Merritt, and B. Zielinska, "Regulated and unregulated emissions from modern 2010 emissions-compliant heavyduty on-highway diesel engines," J. Air Waste Manage. Assoc., vol. 65, no. 8, pp. 987-1001, 2015.

[3] H. J. Kim, S. H. Park, and C. S. Lee, "Impact of fuel spray angles and injection timing on the combustion and emission characteristics of a highspeed diesel engine," Energy, vol. 107, pp. 572-579, 2016.

[4] B. Mohan, W. Yang, and S. K. Chou, "Fuel injection strategies for performance improvement and emissions reduction in compression ignition engines-A review," Renew. Sustain. Energy Rev., vol. 28, no. x, pp. 664-676, 2013.

[5] R. Payri, F. J. Salvador, J. Gimeno, and J. De la Morena, "Effects of nozzle geometry on direct injection diesel engine combustion process," Appl. Therm. Eng., vol. 29, no. 10, pp. 2051-2060, 2009.

[6] R. Payri, J. P. Viera, V. Gopalakrishnan, and P. G. Szymkowicz, "The 
effect of nozzle geometry over internal flow and spray formation for three different fuels," Fuel, vol. 183, pp. 20-33, Nov. 2016.

[7] T. Hulkkonen, T. Sarjovaara, O. Kaario, I. Hamalainen, and M. Larmi, "Experimental Study of Conical Diesel Nozzle Orifice Geometry," At. Sprays, vol. 25, no. 6, pp. 519-538, 2015.

[8] C. Yao, P. Geng, Z. Yin, J. Hu, D. Chen, and Y. Ju, "Impacts of nozzle geometry on spray combustion of high pressure common rail injectors in a constant volume combustion chamber," Fuel, vol. 179, pp. 235-245, Sep. 2016.

[9] N. Mitroglou, M. McLorn, M. Gavaises, C. Soteriou, and M. Winterbourne, “Instantaneous and ensemble average cavitation structures in Diesel micro-channel flow orifices," Fuel, vol. 116, pp. 736-742, 2014.

[10] A. Sou and R. H. Pratama, "Effects of Asymmetric Inflow on Cavitation in Fuel Injector and Discharged Liquid Jet," At. Sprays, vol. 26, no. 9, pp. 939-959, 2016.

[11] J. M. Desantes, R. Payri, F. J. Salvador, and J. De la Morena, "Influence of cavitation phenomenon on primary break-up and spray behavior at stationary conditions," Fuel, vol. 89, no. 10, pp. 3033-3041, 2010.

[12] E. Plamondon and P. Seers, "Development of a simplified dynamic model for a piezoelectric injector using multiple injection strategies with biodiesel/diesel-fuel blends," Appl. Energy, vol. 131, pp. 411-424, 2014.

[13] N. Kawaharada, D. Sakaguchi, H. Ueki, and M. Ishida, "Effects of injector valve movement on diesel spray characteristics under short full valve 
opening," J. Therm. Sci. Technol., vol. 10, no. 2, p. JTST0025-JTST0025, 2015.

[14] R. Payri, F. J. Salvador, M. Carreres, and J. De la Morena, "Fuel temperature influence on the performance of a last generation commonrail diesel ballistic injector. Part II: 1D model development, validation and analysis," Energy Convers. Manag., vol. 114, pp. 376-391, Apr. 2016.

[15] S. Matsumoto, K. Yamada, and K. Date, "Concepts and Evolution of Injector for Common Rail System," SAE Tech. Pap. 2012-01-1753, 2012.

[16] J. E. Johnson, S. H. Yoon, J. D. Naber, S. Lee, G. Hunter, R. Truemner, and T. Harcombe, "Characteristics of 3000 bar Diesel Spray Injection under Non-Vaporizing and Vaporizing Conditions," in ICLASS 2012, 12th Triennial International Conference on Liquid Atomization and Spray Systems, 2012.

[17] J. a Wloka, S. Pflaum, and G. Wachtmeister, "Potential and Challenges of a 3000 Bar Common- Rail Injection System Considering Engine Behavior and Emission Level," SAE Int. J. Engines, vol. 3, no. 1, pp. 801-813, 2010.

[18] O. A. Kuti, J. Zhu, K. Nishida, X. Wang, and Z. Huang, "Characterization of spray and combustion processes of biodiesel fuel injected by diesel engine common rail system," Fuel, vol. 104, pp. 838-846, 2013.

[19] L. M. Pickett and D. L. Siebers, "Soot in diesel fuel jets: Effects of ambient temperature, ambient density, and injection pressure," Combust. Flame, vol. 138[1] L., no. 1-2, pp. 114-135, 2004. 
[20] X. Wang, Z. Huang, W. Zhang, O. Abiola, and K. Nishida, "Effects of ultrahigh injection pressure and micro-hole nozzle on flame structure and soot formation of impinging diesel spray," Appl. Energy, vol. 88, no. 5, pp. 1620-1628, 2011.

[21] A. K. Agarwal, A. Dhar, J. G. Gupta, W. II Kim, K. Choi, C. S. Lee, and S. Park, "Effect of fuel injection pressure and injection timing of Karanja biodiesel blends on fuel spray, engine performance, emissions and combustion characteristics," Energy Convers. Manag., vol. 91, pp. 302314, 2015.

[22] S. Mendez and B. Thirouard, "Using Multiple Injection Strategies in Diesel Combustion: Potential to Improve Emissions, Noise and Fuel Economy Trade-Off in Low CR Engines," SAE Tech. Pap. 2008-01-1329, vol. 1, no. 1, pp. 662-674, 2008.

[23] J. Zhuang, X. Qiao, J. Bai, and Z. Hu, "Effect of injection-strategy on combustion, performance and emission characteristics in a DI-diesel engine fueled with diesel from direct coal liquefaction," Fuel, 2014.

[24] S. H. Park, S. H. Yoon, and C. S. Lee, "Effects of multiple-injection strategies on overall spray behavior, combustion, and emissions reduction characteristics of biodiesel fuel," Appl. Energy, vol. 88, no. 1, pp. 88-98, 2011.

[25] E. Mancaruso, L. Sequino, and B. M. Vaglieco, "Analysis of the pilot injection running Common Rail strategies in a research diesel engine by means of infrared diagnostics and 1d model," Fuel, vol. 178, pp. 188-201, 2016. 
[26] J. O'Connor and M. P. B. Musculus, "Post Injections for Soot Reduction in Diesel Engines: A Review of Current Understanding," SAE Int. J. Engines, vol. 6 , no. 1, pp. 400-421, 2013.

[27] W. Liu and C. Song, "Effect of post injection strategy on regulated exhaust emissions and particulate matter in a HSDI diesel engine," Fuel, vol. 185, pp. 1-9, 2016.

[28] P. Chen, U. Ibrahim, and J. Wang, "Experimental investigation of diesel and biodiesel post injections during active diesel particulate filter regenerations," Fuel, vol. 130, no. x, pp. 286-295, 2014.

[29] G. Bianchi, S. Falfari, F. Brusiani, P. Pelloni, G. Osbat, and M. Parotto, "Numerical Investigation of Critical Issues in Multiple-Injection Strategy Operated by a New CR Fast-Actuation Solenoid Injector," SAE Tech. Pap. 2005-01-1236, 2005.

[30] A. Ferrari and A. Mittica, "Response of different injector typologies to dwell time variations and a hydraulic analysis of closely-coupled and continuous rate shaping injection schedules," Appl. Energy, vol. 169, pp. 899-911, 2016.

[31] F. J. Salvador, J. Gimeno, J. De la Morena, and M. Carreres, "Using onedimensional modeling to analyze the influence of the use of biodiesels on the dynamic behavior of solenoid-operated injectors in common rail systems: Results of the simulations and discussion," Energy Convers. Manag., vol. 54, no. 1, pp. 122-132, 2012.

[32] S. A. GT-Suite, "GT-Suite v.7 user manual," 2010. 
[33] V. Macian, V. Bermúdez, R. Payri, and J. Gimeno, "New technique for determination of internal geometry of a Diesel nozzle with the use of silicone methodology," Exp. Tech., vol. 27, no. April, pp. 39-43, 2003.

[34] W. Bosch, "The Fuel Rate Indicator: a New Measuring Instrument for Display of the Characteristics of Individual Injection," SAE Pap. 660749, 1966.

[35] R. Payri, F. J. Salvador, J. Gimeno, and G. Bracho, "A new methodology for correcting the signal cumulative phenomenon on injection rate measurements," Exp. Tech., vol. 32, no. February, pp. 46-49, 2008.

[36] A. K. Lichtarowicz, R. K. Duggins, and E. Markland, "Discharge coefficients for incompressible non-cavitating flow through long orifices," J. Mech. Eng. Sci., vol. 7, no. 2, pp. 210-219, 1965.

[37] R. Payri, F. J. Salvador, J. Gimeno, and J. De la Morena, "Study of cavitation phenomena based on a technique for visualizing bubbles in a liquid pressurized chamber," Int. J. Heat Fluid Flow, vol. 30, no. 4, pp. 768-777, 2009.

[38] W. H. Nurick, "Orifice cavitation and its effects on spray mixing," J. Fluids Eng., vol. 98, pp. 681-687, 1976.

[39] C. Jörg, T. Schnorbus, S. Jarvis, B. Neaves, K. Bandila, and D. Neumann, "Feedforward Control Approach for Digital Combustion Rate Shaping Realizing Predefined Combustion Processes," SAE Int. J. Engines, vol. 8, no. 3, pp. 1041-1054, 2015. 
[40] B.Huber and H.Ulbrich, "Modeling and Experimenta Validation of the Solenoid Valve of a Common Rail Diesel Injector," SAE Technical Paper 2014-01-0195, 2014, doi:10.4271/2014-01-0195

[41] A.Ferrari,A.Mirrica,F.Paolicelli,P.Pizzo, "Hydraulic characterization of solenoid-actuated injectors for diesel engine Common Rail systems," Energy Procedia, Volume 101, 2016, pp. 878-885.

[42] A.Piano F.Millo "Numerical and Experimental Assessment of a Solenoid Common-Rail Injector Operation with Advanced Injection Strategies," SAE International doi:10.4271/2016-01-0563. 


\section{APPENDIX A}

\begin{tabular}{|lcc|}
\hline Element & Length [mm] & Area [mm2] \\
\hline MF1 & 7.32 & 58.4 \\
MF2 & 2.78 & - \\
MF3 & 7.32 & 65.4 \\
MF4 & 30.78 & - \\
AirGap & 0.15 & 73 \\
& No.coils [-] & Int.Resistance \\
& & $\mathbf{( \Omega )}$ \\
Coil & 40 & 0.63 \\
\hline \multicolumn{2}{l}{ Main magnetic elements of solenoid circuit }
\end{tabular}

\begin{tabular}{|c|c|c|c|c|}
\hline Element & $\begin{array}{l}\text { Length } \\
{[\mathrm{mm}]}\end{array}$ & $\begin{array}{c}\text { Volume } \\
{\left[\mathrm{mm}^{3}\right]}\end{array}$ & $\begin{array}{l}\text { Diameter } \\
\text { [mm] }\end{array}$ & $\begin{array}{l}\text { Mass } \\
\text { [g] }\end{array}$ \\
\hline V7 & & 272.4 & - & 200 \\
\hline V6 & - & 366.7 & - & - \\
\hline L8 & 50 & - & 5 & - \\
\hline PipeRound-4 & 0.5 & - & 1 & 1 \\
\hline \multirow[t]{2}{*}{ CtrlValveMass } & & - & & 3.35 \\
\hline & \multicolumn{2}{|c|}{$\begin{array}{l}\text { Piston Diameter } \\
{[\mathrm{mm}]}\end{array}$} & \multicolumn{2}{|c|}{$\begin{array}{l}\text { Rod Diameter } \\
{[\mathrm{mm}]}\end{array}$} \\
\hline FluidPiston-5 & \multicolumn{2}{|c|}{15.5} & \multicolumn{2}{|c|}{1.85} \\
\hline FluidPiston-4 & \multirow{2}{*}{\multicolumn{2}{|c|}{$\begin{array}{l}13.2 \\
165\end{array}$}} & \multicolumn{2}{|l|}{4.34} \\
\hline ControlValve1 & & & \multicolumn{2}{|l|}{0.99} \\
\hline \multirow[t]{2}{*}{ FlapperValve-2 } & \multicolumn{2}{|c|}{$\begin{array}{l}1.05 \\
175\end{array}$} & 1.07 & \\
\hline & \multicolumn{2}{|c|}{ Stiffness [N/m] } & \multicolumn{2}{|l|}{ reload [N] } \\
\hline CtrlVlvSpring & & & -30 & \\
\hline
\end{tabular}

\begin{tabular}{|lcc|}
\hline Element & $\begin{array}{c}\text { Volume } \\
{\left[\mathrm{mm}^{3}\right]}\end{array}$ & Diameter $[\mathrm{mm}]$ \\
\hline OA & - & 0.229 \\
OZ & - & 0.187 \\
V3 & 3 & - \\
V2 & 55 & - \\
\hline
\end{tabular}


V1 125

Main elements of Control Volume

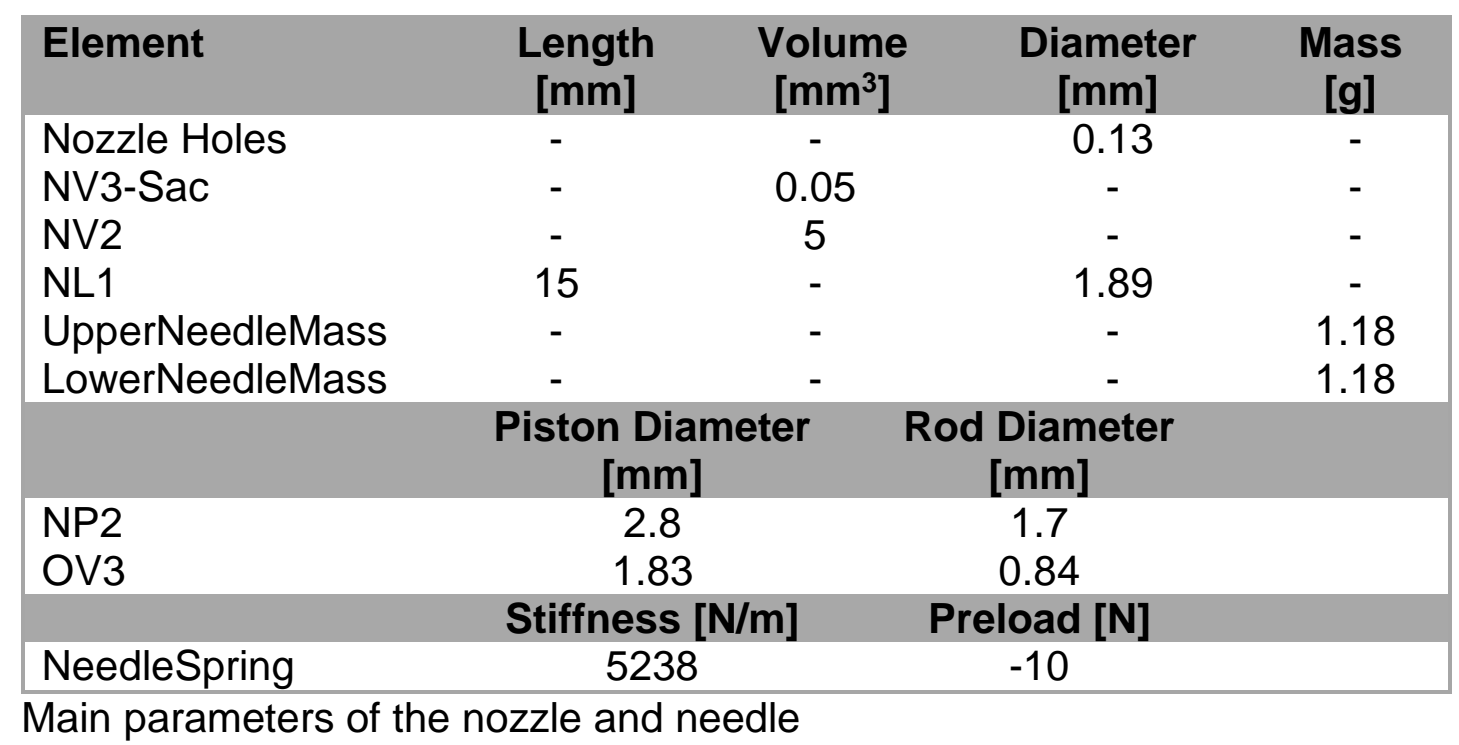

\begin{tabular}{|c|c|c|c|c|}
\hline Element & $\begin{array}{l}\text { Length } \\
{[\mathrm{mm}]}\end{array}$ & $\begin{array}{l}\text { Volume } \\
{\left[\mathrm{mm}^{3}\right]}\end{array}$ & $\begin{array}{l}\text { Diameter } \\
{[\mathrm{mm}]}\end{array}$ & Mass [g] \\
\hline EdgeFilter & - & 115 & - & - \\
\hline V5 & - & 120 & - & - \\
\hline L1 & 10 & - & 1.36 & - \\
\hline L2 & 7.22 & - & 1.22 & - \\
\hline L6 & 58 & - & 1.35 & - \\
\hline UpperCtrlPistonMas & 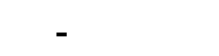 & - & - & 5.48 \\
\hline \multirow{3}{*}{$\begin{array}{l}\text { S } \\
\text { LowerCtrlPistonMas } \\
\mathrm{S}\end{array}$} & - & - & - & 5.48 \\
\hline & & & & \\
\hline & $\begin{array}{l}\text { Piston } \\
\text { Diameter } \\
\text { [mm] }\end{array}$ & \multicolumn{2}{|c|}{$\begin{array}{l}\text { Rod } \\
\text { Diameter } \\
\text { [mm] }\end{array}$} & $\begin{array}{l}\text { Radial } \\
\text { Clearance } \\
{[\mathrm{mm}]}\end{array}$ \\
\hline CtrlPistonFace & 3.9 & \multicolumn{2}{|c|}{1.75} & - \\
\hline LeakagePastPis & 3.9 & \multirow{2}{*}{\multicolumn{2}{|c|}{2.9}} & 0.005 \\
\hline RodForce & 3.9 & & & - \\
\hline $\mathrm{FFI} 2$ & 3.41 & & - & 0.005 \\
\hline
\end{tabular}





\section{Nomenclature}

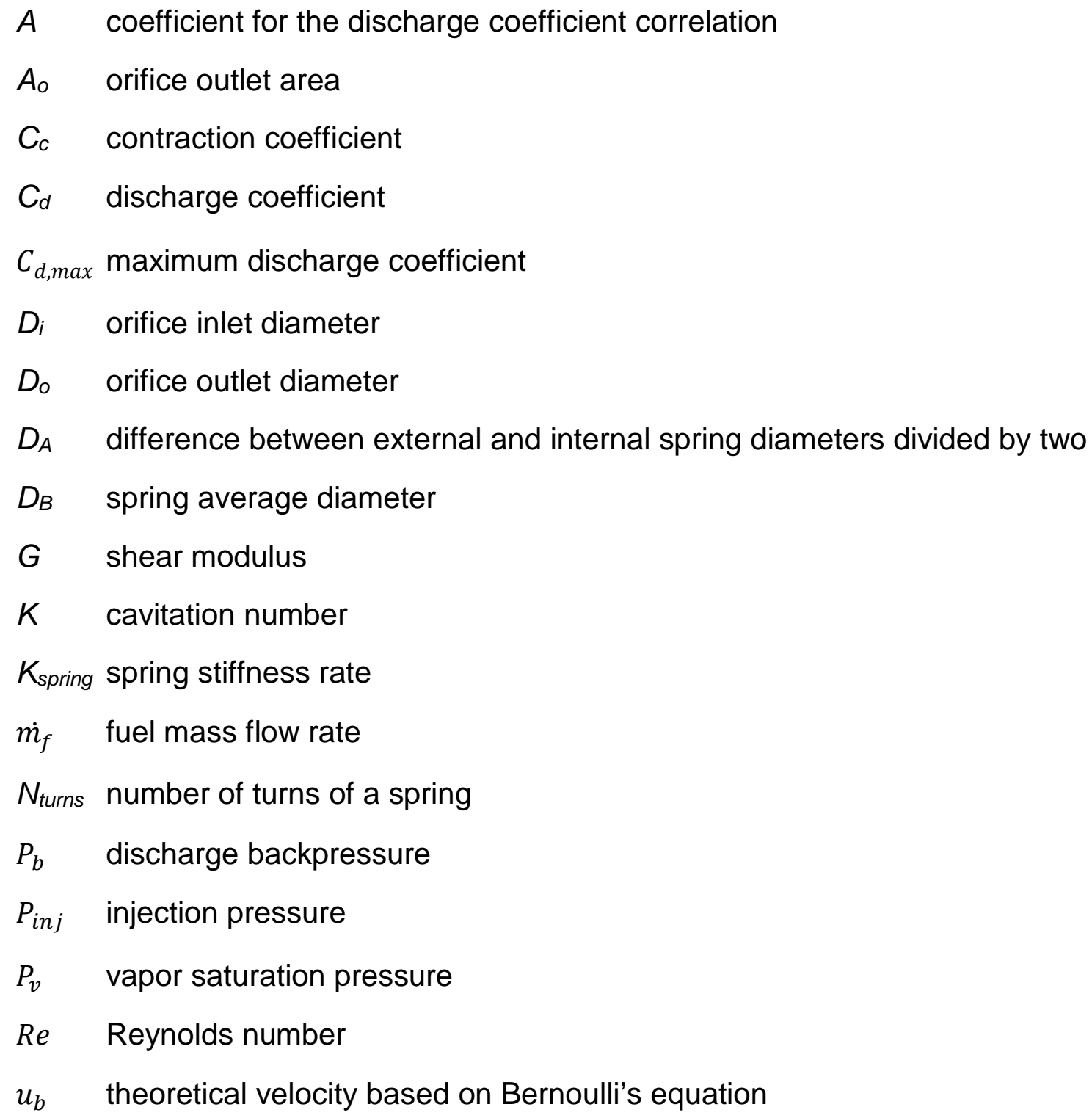

\section{Greek symbols}

$\Delta p \quad$ pressure drop

$\rho_{f} \quad$ fuel density

\section{Abbreviations}

DT dwell time

ET1 energizing time of the first injection

ET2 energizing time of the second injection 
OA control volume outlet orifice

$\mathrm{OZ}$ control volume inlet orifice

ROI Rate of Injection

SEM Scanning Electron Microscope

CP Constant Rail Pressure

VP Variable Rail Pressure 